IZA DP No. 7608

Intergenerational Occupational Mobility in India

Mehtabul Azam

September 2013

Forschungsinstitut zur Zukunft der Arbeit Institute for the Study of Labor 


\title{
Intergenerational Occupational Mobility in India
}

\author{
Mehtabul Azam \\ Oklahoma State University \\ and IZA
}

\section{Discussion Paper No. 7608 \\ September 2013}

\author{
IZA \\ P.O. Box 7240 \\ 53072 Bonn \\ Germany \\ Phone: +49-228-3894-0 \\ Fax: +49-228-3894-180 \\ E-mail: iza@iza.org
}

Any opinions expressed here are those of the author(s) and not those of IZA. Research published in this series may include views on policy, but the institute itself takes no institutional policy positions. The IZA research network is committed to the IZA Guiding Principles of Research Integrity.

The Institute for the Study of Labor (IZA) in Bonn is a local and virtual international research center and a place of communication between science, politics and business. IZA is an independent nonprofit organization supported by Deutsche Post Foundation. The center is associated with the University of Bonn and offers a stimulating research environment through its international network, workshops and conferences, data service, project support, research visits and doctoral program. IZA engages in (i) original and internationally competitive research in all fields of labor economics, (ii) development of policy concepts, and (iii) dissemination of research results and concepts to the interested public.

IZA Discussion Papers often represent preliminary work and are circulated to encourage discussion. Citation of such a paper should account for its provisional character. A revised version may be available directly from the author. 
IZA Discussion Paper No. 7608

September 2013

\section{ABSTRACT}

\section{Intergenerational Occupational Mobility in India*}

In this paper, we examine the intergenerational occupational mobility in India among men born during 1945-85. Following Long and Ferrie (2013, American Economic Review), we not only distinguish between prevalence and association, but also use the Altham Statistics which involves comparison of all possible odds ratios, for example, the odds that the son of a white collar father would get a white collar job compared with the odds that the son of a lowskilled father would get a white collar job - as measure of distance between son-father occupation associations across cohorts. We extend the analysis to the differences in mobility across social groups, and attempt to isolate the specific odds ratios that account for the largest part of the difference. We find no evidence of difference in mobility in successive ten year birth cohorts; however, looking at the longer time period (birth cohort 1945-54 vs. 197584), we find that the mobility in the 1975-84 birth cohort is higher than the mobility in the 1945-54 birth cohort. Although the mobility among Scheduled Castes/Tribes (SC/STs) in the 1945-64 birth cohort was not different than the mobility observed in the entire 1945-64 birth cohort, SC/STs born during 1965-84 experienced a higher mobility when compared with the entire 1965-84 birth cohort. Similarly, when compared with the higher castes, SC/STs experienced lower mobility in the 1945-64 birth cohort; however, the mobility among SC/STs has been higher than the mobility among higher castes in the 1965-84 birth cohort.

JEL Classification: J62

Keywords: intergenerational mobility, occupation, India, caste

Corresponding author:

Mehtabul Azam

326 Business Building

Spears School of Business

Oklahoma State University

Stillwater, OK 74078

USA

E-mail: mazam@okstate.edu

\footnotetext{
*I am grateful to Sonia Bhalhotra, Pradeep Mitra and Tauhidur Rahman for helpful comments. All the errors remain mine.
} 


\section{Introduction}

The belief that personal history determines destiny in India, mostly based on the caste system is quite pervasive. Historically, Indian society had been stratified on the caste lines which were initially developed based on the occupation (Despande, 2000). Occupational mobility has been considered important per se as societies where occupations and positions are fixed and set at birth, and are transmitted from father to child through rigid schemes have little room for innovation and fulfillment at either the individual or collective level (Bourdieu et al., 2006), and appropriately has attracted considerable attention across many countries. There exists a considerable literature for developed countries (Ferrie, 2005; Hellerstein and Morrill, 2008; Ermish and Francesconi, 2002); however, given a much higher importance of intergenerational mobility in the Indian context because of stratified society and caste system, there exists comparatively limited literature (discussed in Section 1.1) probably because of lack of suitable data to carry out such studies. ${ }^{1}$

In this paper, we address the issue of intergenerational occupational mobility in India for men born during 1945-1984. We use nationally representative India Human Development Survey (IHDS) data in which we are able to find the fathers' occupations for majority of adult males because of couple of specific questions which the IHDS contained but which are not available in other widely used data sets in India such as National Sample Survey (NSS) or National Family Health Survey (discussed in detail in data section). We aggregate occupations into four broader occupation categories---white collar, skilled/semi-skilled, unskilled (include agriculture laborers), and farmers---and use contingency tables to document changes in occupation-specific human capital transmission between fathers and sons spanning birth cohorts

\footnotetext{
${ }^{1}$ An overview of cross-country evidence on occupational mobility can be found in Blanden (2009).
} 
from 1945 to 1984 and among social groups. ${ }^{2}$ When measuring mobility within a single contingency table or changes in mobility across several tables, it is useful to distinguish between absolute and relative mobility. Change in absolute mobility - the observed amount of movement out of one category and into another-is the effect of both changes in the marginal distributions of occupations (changes in "prevalence") and changes in the underlying relationship between occupations across generations (changes in “association”) (Ferrie, 2005).

Changes in mobility patterns in the long run may result either from an evolution of the economic structure, for example due to industrialization or from changes in the degree of openness of the society. For instance, the possibility of becoming a farmer declines as the proportion of farmers in the economy declines, whereas the opportunity of becoming a lawyer may grow, without any changes in the proportion of lawyer in the society, as more and more people have access to education (Bourdieu et al., 2006). Thus prevalence could change if economic growth prompts a shift in employment from one category (farmer) to another (white collar). Association could change because of a weakening in the impediments to mobility (educational requirements, the strength of crafts or guilds, the importance of social networks) that improves the chance for some groups moving into an occupation (sons of farmers moving into white collar jobs) by more than it improved the chances of others moving into the same occupation (sons of white collar workers moving into white collar jobs themselves) (Ferrie, 2005).

Hence, to disentangle the association from prevalence, we also compute mobility measures adjusting for differences in occupation distribution across cohorts and social groups.

\footnotetext{
${ }^{2}$ Some of the studies examine intergenerational generational transmission between fathers and sons (see, e.g., DiPrete and Grusky, 1990) by estimating the correlation in occupational prestige index---an index which ranks occupations. However, there exists no occupation prestige index for India.
} 
Moreover, following Long and Ferrie (2013, 2007), Altham and Ferrie (2008), and Ferrie (2005), we use the Altham statistics, which involves comparison of all possible odds ratios, as fundamental measure of mobility, and isolate the specific odds ratios that account for the largest part of the difference between the associations in two contingency tables. As, the estimates may differ based on the way we aggregate occupations, we also show that our results are qualitatively similar if we aggregate the occupations in substantially large number of groups rather than only four groups.

The paper contributes to the existing literature in the following ways. First, to our best knowledge, the paper is first to use the Altham Statistics in the Indian or developing country context as a measure of distance between son-father occupation associations across cohorts/social groups. The use of the Altham statistics allows us to isolate the specific odds ratios that account for the largest part of the difference in son-father associations across cohorts/social groups. Second, the paper also distinguishes between prevalence and association, which is important in the Indian context as the structure of the Indian economy has been changing over time. Third, the paper is able to match majority of adult males to their fathers' occupation and tracks the occupational mobility over time for the entire population and specific social groups. ${ }^{3}$

The findings of the paper are as follows. First, there is no strong evidence for change in mobility in successive ten year birth cohorts except between the 1965-74 and 1975-84 birth cohorts. Looking at a longer horizon, between birth cohorts 1945-54 and 1975-84, the simple measure of mobility suggests a decline in mobility, however, the more robust Altham statistics suggests higher mobility in the 1975-84 birth cohort compared with mobility in the 1945-54 birth

\footnotetext{
${ }^{3}$ As discussed in Section 1.1, Motiram and Singh (2012) also report matrix based indices for the birth cohorts. However, our paper in addition to tracking mobility across birth cohorts, also tracks mobility for different social groups over time, and study the differences across social groups by birth cohorts rather than differences across social group for the entire adult male population.
} 
cohort. The findings remain qualitatively similar when we aggregate occupations in nine categories rather than four categories. Second, although mobility among different social groups has not been different than the mobility observed among the entire population in the birth cohort 1945-64, the mobility among higher castes and SC/STs born during 1965-84 has been higher than the mobility in the entire 1965-84 birth cohort. Third, SC/STs had a lower mobility when compared with higher castes in the birth cohort 1945-64; however, they experienced a higher mobility than the higher castes in the birth cohort 1965-84.

The remainder of the paper is organized as follows. Section 1.1 presents a brief review of the existing literature on the intergenerational occupational mobility in India, and how our paper differs from them. Section 2 discusses the data, and the approach used to create a father-son matched data for India. Section 3 outlines the conceptual framework underlying our empirical analysis. Section 4 presents the results, and Section 5 concludes.

\subsection{Related Literature}

The study of intergenerational mobility in India is hampered by lack of suitable datasets. To our best knowledge, there exists no long term panel data or nationally representative cross-sectional data which contain fathers' information for all adult persons. Kumar et al. (2002a, 2002b) use electorate data from the Center for the Study of Developing Societies (CSDS) to study the intergenerational occupational mobility in India. This data is based upon random sampling of the

Indian electorate in 1971 and in 1996. Their sample consist 1809 son-father pair in 1971 and 3740 son-father pair in 1996. They also distinguish between changes in structure and fluidity. Kumar et al (2002b) analysis comparing inter-generational mobility in 1971 with 1996 finds limited mobility, though such mobility was somewhat greater in 1996 (71 per cent remained in their father's occupation) than in 1971 (75 percent remained in their father's occupation). 
Recently some attempts have been made to study the intergenerational occupational mobility in India using the nationally representative cross-section data collected by National Sample Survey (Majumdar 2010; Hnatkovska et al. 2011). Hnatkovskay et al. (2012) use five rounds of NSS surveys (1983, 1987-88, 1993-94, 1999-00, and 2004-05), and aggregate occupations in three groups (white collar, blue collar and agriculture). Based on occupation switches (sons' occupation being different than fathers' occupation, similar to our simple measure of mobility), they find that the overall probability of an occupation switch by next generation relative to the household head has steadily increased from 32 percent in 1983 to 41 percent in 2004-05. For non-SC/STs the switch probability increased from 33 percent to 42 percent while for SC/STs it has gone from 30 to 39 percent. They conclude that difference in intergenerational mobility between SC/STs and non-SC/STs has not changed over this period.

Besides only presenting simple measure of mobility, Hnatkovskay et al. (2012) data (NSS surveys in spite of being large scale cross-sections) imposes limitations that have implications for intergenerational mobility estimates. NSS only collects information about the individuals living in household at the time of survey and provide each individual relation with the head of the household. Identification of father is achieved through exploiting the relation to head variable (head is considered father, and son of the head is considered son). Azam and Bhatt (2012) demonstrate that in a typical NSS cross section data (using 2004-05 data), one can identify fathers for only about 27 percent of adult male members between the age group 20-65 as almost more 62 percent of males in age group 20-65 are classified as household heads. Moreover, more than 80 percent for whom father education information can be found belong to age 20-30 age group. The problem of identifying fathers information is exacerbated in case of occupation, as unlike education which is reported for all the members living in the household, occupation is 
reported only if the member is working at the time of survey. Technically, Hnatkovskay et al. (2012) do not use a pure son-father sample as they take all male households heads in age 16-65 as fathers and their male children/grandchildren between the ages 16 and 65 as sons, thus include grandchildren in their sons sample also. Nevertheless, in spite of that the success rate of finding father's information is pretty low. For example, they report number of observations (son-father pair) of 24,$119 ; 28,149 ; 25,716 ; 25,994 ;$ and 27,051 in $1983,1987-88,1993-94,1999-00$, and 2004-05; while the actual number of males in age group 16-65 surveyed in these cross-sections are 177,$008 ; 196,412 ; 173,182 ; 183,732 ;$ and $188,585 .{ }^{4}$ Hence they found father's information for only $13.7,14.3,14.9,14.2$, and 14.4 percent of individuals in age group 16-65 in 1983, 198788, 1993-94, 1999-00, and 2004-05. We believe that the very low success rate of matching is worth documenting, and in the extreme scenario of strong sample selection, the sample of successfully matched cases would have provided little identifying information about the general population to which the authors wish to generalize (Manski, 1995). In addition to pretty low success rate in finding fathers' information, they provide the cross sectional estimates for five successive cross-sections separated by five year. Given the low success rate of matching fathers' information and cross sectional nature of estimates, the information provided by estimates has their own limitations. ${ }^{5}$ In data section, we discuss how we are able to identify fathers' occupations for majority of adult men.

\footnotetext{
4 Table S7: Intergenerational occupational switches: Estimation results, of Hnatkovskay et al. (online appendix) report the sample sizes that they have used, while the actual number of male in age group 16-65 surveyed are obtained from NSS data sets.

${ }^{5}$ Azam and Bhatt (2013) showed the sons for whom fathers information can be identified mostly belong to $20-30$ age group (more than 80 percent of total identified sample), and there are hardly any sons in higher age group (40-65 age group) for whom father is found living in the same household. In addition, the life cycle biases, if any, should be at maximum, as in the identified son-father pair in which both son and father is working at the time of survey, one would expect that father is probably at the last stage of his career while son is probably at the beginning of his career. This was indeed the case with Hnatkovskay et al. (2012) sample as the household-heads in their sample are around 52 years of age while their male working children are typically around 23 years old.
} 
Motiram and Singh (2012) also use the IHDS data as used in our paper. ${ }^{6}$ In addition to transition matrices, they present mobility measures $M_{1}$ : probability that a son (or the expected proportion of sons) will leave the father's occupational category and measures based on eigenvalues of transition matrices for SC/STs and non-ST/STs, rural/urban, and age cohorts. ${ }^{7}$ They report a considerable intergenerational occupational persistence-across all occupational categories, the father's category is the most likely one that a son could find himself in (e.g. a likelihood of almost half for agricultural laborers). But, there are differences across occupational categories - the probability that a son would fall in the father's category is higher for the lowskilled/low-paying occupations. They also find that mobility is higher in urban areas as compared to rural areas. Comparison of mobility for SC/STs and non-SC/STs gives ambiguous results. However, they document considerable downward mobility for the SC/STs and show that this is higher than the same for non-SC/STs. For SC/STs, they also observe higher persistence (as compared to the same for non-SC/STs) in low-skilled/low-paying occupations.

Our study differs from Hnatkovskay et al. (2012) and Motiram and Singh (2012) in the following ways. First, unlike Hnatkovskay et al. (2012), we are able to identify fathers' occupations for majority of adult males, and provide occupation-specific human capital transmission between fathers and sons spanning birth cohorts from 1945 to 1984 . Second, although similar to Hnatkovskay et al. and Motiram and Singh, we present the simple measure of mobility (as measured by off-diagonal elements); however, we further distinguish between

\footnotetext{
${ }^{6}$ Our sample is much larger than the sample used by Motiram and Singh (2012). As reported in appendix-1, Table A1, our final sample consists of 38,294 son-father pairs. While our sample is restricted to males in age group 21-60, Motiram and Singh restrict their sample to males in age group 20-65. In spite of a larger age band used, they report a sample of 28,270 son-father pair (footnote of Table-1 of Motiran and Singh). As they have not provided details of sample construction, we are unable to comment on their smaller sample. Our data appendix and appendix-1, Table A1 provide our sample construction in detail.

${ }^{7}$ They report $M_{3}=1-\left|\lambda_{2}\right|$ and $M_{4}=1-\left|\prod_{=1}^{m} \lambda_{i}\right|$, where $\lambda_{2}$ is second largest eigenvalue of transition matrix and $\lambda_{i}$ are eigenvalues of transition matrix.
} 
prevalence and associations. We estimate mobility measures after adjusting for differences in occupation distributions. We think this is important as economy has been undergoing through structural changes, and also corroborated by our findings (reported in results section) that after adjusting for differences in occupation distributions, many of the conclusions based on simple measure of mobility is changed. Moreover, following Ferrie (2005), Altham and Ferrie (2008), and Long and Ferrie (2013), we estimate the Altham statistics, which provide a distance measure between son-father occupation associations for two different cohorts/social groups. We also test whether the difference in son-father occupation associations between two cohorts/groups is nonzero. In addition, we further decompose the distance in associations to provide answers how much and in which odds ratios, the son-father occupation association differ across birth cohorts/groups.

\section{Data}

We use data from the India Human Development Survey, 2005 (IHDS), a nationally representative survey of households jointly organized by the National Council of Applied Economic Research (NCAER) and the University of Maryland. The IHDS covers 41,554 households in 1503 villages and 971 urban neighborhoods located throughout India. ${ }^{8}$ The survey was conducted between November 2004 and October 2005 and collected a wealth of information on education, caste membership, health, employment, marriage, fertility, and geographical location of the household.

One of the major hindrances in carrying out any intergenerational study in developing countries is lack of long panel data. In India, this problem is exacerbated as none of the large

\footnotetext{
${ }^{8}$ The survey covered all the states and union territories of India except Andaman and Nicobar, and Lakshadweep. These two account for less than .05 percent of India's population. The data is publicly available from the Data Sharing for Demographic Research program of the Inter-university Consortium for Political and Social Research (ICPSR).
} 
cross sections (such as NSS or NFHS) collect information about father for all surveyed persons.

As noted in earlier discussion (section 1.1), the identification of father using the co-residence lead to a sample which suffers from selection. ${ }^{9}$ In contrast to the NSS and the NFHS, the IHDS data has asked specific questions regarding the education and occupation of household head's father/husband (irrespective of the father/husband living in the household or not). ${ }^{10}$ In addition, the IHDS also provides ID of father in the household roster which helps linking individuals to their fathers directly if the father is living in the household. Combining these two variables, we are able to identify fathers' occupation for majority of male adults (21-60). A full description of data construction is provided in appendix 1, Table1 and data appendix. There are certain limitations of data for carrying out the task. First, optimally, one should have father and son's occupation at the same age. However, in our data, son's occupation is the self-reported occupation in the past year, while for majority of fathers; the occupation is the occupation for most of father's life as reported by son. ${ }^{11,12}$ Second, since we identify son's occupation using the self-reported occupation in the past year, it implies that we are using son's occupation at different points of their career based on their age. ${ }^{13}$ Although, the data is not the ideal for carrying out an intergenerational occupational mobility task, it is a significant way forward given

\footnotetext{
${ }^{9}$ Azam and Bhatt (2013) demonstrate that majority of adult males are household head themselves, and do not have father living in the same households (or perhaps deceased), and this fact is also corroborated in appendix Table 1. ${ }^{10}$ Question 1.19 and 1.20 on page 3 of the Household Questionnaire.

${ }^{11}$ As noted earlier and shown in Appendix1, Table 1, majority (almost more than 60 percent) of men in age group 20-65 are household heads, and their fathers' occupation is obtained from the question "What was the occupation of the household head's father (for most of his life)?" For rest of the individuals who are not households heads, the fathers occupation is based on observed occupation of father in the past year if the father is co-resident in the same household.

${ }^{12}$ One advantage of measuring intergenerational mobility by class or occupation is that the data restrictions are much less stringent, retrospective information on father's occupation is not difficult to collect and does not require the investment in longitudinal data necessary for intergenerational income studies (Blanden, 2009).

${ }^{13}$ Ex-ante, it is difficult to assess the life-cycle bias as there exists no nationally representative study on intragenerational occupational mobility. However, the existing evidences based on case studies suggest that the life-cycle bias may not be that strong. For example, Munshi and Rosenzweig (2009) document the lack of labor mobility in India. Moreover, one may also think that occupation, broadly defined, varies less over the lifecycle making agerelated biases less problematic (Blanden, 2009).
} 
the data constraints for such study in India. We have occupation information of fathers for majority of adult male surveyed in nationally representative IHDS. ${ }^{14}$

Unlike income which is a continuous variable, the occupations are reported in two digits occupation codes, and one need to aggregate the categories in few categories to get transition matrices. The consensus on the classificatory schemes in the literature on mobility is lacking and different authors have used different schemes, even when they have examined the same country (e.g. Long and Ferrie 2005; Erikson and Goldthorpe 1992). We classify the occupation in four groups: white collar workers, skilled/semi-skilled workers, unskilled workers (includes agricultural wage workers), and farmers. Appendix 3 shows how we grouped the 2-digit occupation codes to arrive at four groups. To examine the sensitivity of our findings with respect to aggregation of occupations, we alternatively aggregated using the first digit of occupation codes (in nine groups). We find qualitatively similar results with nine occupation groups.

\section{Empirical Methodology}

In this paper, we follow the methodology used in Long and Ferrie $(2013,2007)$, Altham and Ferrie (2008), and Ferrie (2005), to compare the mobility across time and groups. Following the literature on mobility, we first present the transition matrices, with categories for fathers' occupations arrayed across one dimension and categories for sons' occupations arrayed across the other. However, comparing mobility across two time period or two social groups require comparing two matrices. One simple measure of the overall mobility in matrix $P=\left[\begin{array}{ll}p_{11} & p_{12} \\ p_{21} & p_{22}\end{array}\right]$,

\footnotetext{
${ }^{14}$ As noted by Xie and Killwald (2013), we also do not wish to convey that data sources for measuring social mobility in other countries/studies are flawless. We only wish to pinpoint some of the limitations of our data, and how it is a significant improvement over the existing literature. Since an ideal data do not exist in the given context, we have to rely on the existing data source and minimize the bias, which we claim to be doing by using a sample which identify fathers information for majority of adult men in age group 20-65, and potentially reducing the lifecycle bias, if there exists any, as we are using fathers' occupation in which father spent most of his life time.
} 
with number of fathers in two occupations (1 or 2$)$ in columns and number of sons in these occupations in rows, used in the literature, is the fraction of off-diagonal elements, i.e. fraction of sons who end up in jobs different from those of their fathers: $M_{p}=\left(p_{12}+p_{21}\right) /\left(p_{11}+p_{12}+\right.$ $\left.p_{21}+p_{22}\right){ }^{15}$ However, as discussed in Altham and Ferrie; Ferrie; and Long and Ferrie, the simple measure of mobility $M_{p}$ has shortcomings when mobility is compared across two transition matrices $P$ and $Q$ : it does not distinguish between differences in mobility (1) arising from differences across the matrices in the distributions of fathers' and sons' occupations and (2) arising from differences across the matrices in the association between father's and sons' jobs that may occur even if the distributions of fathers' and sons' occupations were identical in $P$ and $Q$

Consider $P=\left[\begin{array}{ll}3 & 1 \\ 2 & 2\end{array}\right]$ and $Q=\left[\begin{array}{ll}2 & 1 \\ 6 & 1\end{array}\right]$ for which $M_{p}=3 / 8$ and $M_{Q}=7 / 10$. As the marginal frequencies differ, it's unclear whether the differences in observed mobility $M$ results from differences in marginal frequencies or from something more fundamental such as differences between $P$ and $Q$ in the amount of human capital necessary to achieve job 1 (Long and Ferrie). One way to proceed is to adjust one of the matrices so it has the same marginal frequencies by multiplication of rows and columns by arbitrary constants. As discussed in detail in Altham and Ferrie, multiplying the rows and columns of a matrix by arbitrary constants does not alter the underlying association between rows and columns in the matrix. If we multiply the first row of $Q$ by 2 and then multiply the first column by $1 / 2$, we get a new matrix $Q^{\prime}=\left[\begin{array}{ll}2 & 2 \\ 3 & 1\end{array}\right]$ with the same marginal frequencies as in matrix $P$, with the associated total mobility measure $M_{Q^{\prime}}=5 / 8$ (Long and Ferrie). Then we can calculate the difference $M_{P}-M_{Q^{\prime}}$ and be confident

\footnotetext{
${ }^{15} p_{12}$ is the number of sons of job 1 fathers who themselves obtained job 2.
} 
that the difference in mobility does not result from differences in the distributions of occupations between the two time periods or groups. This is still somewhat unsatisfactory as focusing on offdiagonal elements but treating all moves identically discards a great deal of potentially useful information (Long and Ferrie, 2007)

The fundamental measure of association between rows and columns in a mobility table is the cross-product ratio, which for $P$ is $p_{11} p_{22} / p_{12} p_{21}$ and can be rearranged to give $\left(\frac{p_{11}}{p_{12}}\right) /$ $\left(\frac{p_{21}}{p_{22}}\right)$, the ratio of (1) the odds that sons of job 1 fathers get job 1 rather than job 2 to (2) the odds that sons of job 2 fathers get job 1 rather than job 2. If there is perfect mobility, the crossproduct ratio would be one: sons of job 1 fathers would have no advantage in getting job 1 relative to sons of job 2 fathers. The more the cross-product ratio exceeds one, the greater the relative advantage of having a job 1 father in getting job 1.

For a table with more than two rows or columns, there are several cross-products ratios. Altham (1970) proposed a measure of the difference in relative mobility between two transition matrices that is based solely on the odds ratios, and takes account of the full set of cross-products ratios. For two tables $P$ and $Q$ each have $r$ rows and $s$ columns, the Altham statistic $d(P, Q)$ :

$$
d(P, Q)=\left[\sum_{i=1}^{r} \sum_{j=1}^{s} \sum_{l=1}^{r} \sum_{m=1}^{s}\left|\log \left(\frac{p_{i j} p_{l m} q_{i m} q_{l j}}{p_{i m} p_{l j} q_{i j} q_{l m}}\right)^{2}\right|\right]^{1 / 2}
$$

For two tables $P$ and $Q$, the Altham statistic $d(P, Q)$ measures the difference between 1$)$ the association between rows and columns in Table $P$ and 2) the association between rows and 
columns in Table $Q .{ }^{16}$ Replacing one table with a table of ones allows us to calculate $d(P, I)$ and $d(Q, I)$, the distance between the association between rows and columns in Table $P$ or $Q$ and the association between rows and columns in a table in which rows and columns are independent. These distance measures have likelihood ratio chi-square test statistics $\left(G^{2}\right)$ to test the null hypothesis that the associations do not differ, so one can assess whether two tables differ from each other and from independence (Altham and Ferrie, 2007). If $d(P, I)<d(Q, I)$ and $d(P, Q) \neq 0$, then Table $P$ has greater mobility than Table $Q$ (that is, Table $P$ has an association between rows and columns that is closer to what we would observe under independence than does Table $Q$ ).

The Altham statistic is a pure function of the odds ratios in each table, so it is not affected by differences in the marginal frequencies (Ferrie, 2005). In addition, as $[d(P, Q)]^{2}$ is a simple sum of the squares of log odds ratio contrasts, it can be decomposed into its constituent elements: for an $r \times s$ table, there will be $[r(r-1) / 2][s(s-1) / 2]$ odds ratios in $d(P, Q)$ and it will be possible to calculate how much each contributes to $[d(P, Q)]^{2}$, in the process identifying the locations in $P$ and $Q$ where the differences between them are greatest.

As contingency tables are often dominated by diagonal elements, we also calculate another version of $d(P, Q)$ that examines only the off-diagonal cells to see whether, conditional on occupational mobility occurring between fathers and sons, the resulting patterns of mobility are similar in $P$ and $Q$. This new statistic will then test whether $P$ and $Q$ differ in their proximity to "quasi-independence." (Agresti, 2002, p. 426) For square contingency tables with $r$ rows and

\footnotetext{
${ }^{16}$ Altham and Ferrie (2007) discuss the distance measure and test statistic, and provide STATA algorithms for their computation. In this paper, we have used the STATA algorithm provided in Altham and Ferrie.
} 
$s$ columns, this additional statistic $d^{i}(P, Q)$ will have the same properties as $d(P, Q)$, but the likelihood ratio $\chi^{2}$ statistic $G^{2}$ will have $\left[(r-1)^{2}-r\right]$ degrees of freedom.

Similar to Long and Ferrie, Altham and Ferrie, and Ferrie, we also proceed in three steps:

First, we calculate total mobility for each table as the ratio of the sum of the off-diagonal elements to the total number of observations in the table, and find the difference in total mobility between $P$ and $Q$;

Second, we adjust one of the tables to have the same marginal frequencies as the other and recalculate the difference in total mobility to eliminate the influence of differences in the distribution of occupations;

Third, we calculate $d(P, Q), d^{i}(P, Q), d(P, I)$, and $d(Q, I)$ and the likelihood ratio $\chi^{2}$ statistics $G^{2}$; if $d(P, Q) \neq 0$, we calculate the full set of log odds ratio contrasts and identify those making the greatest contribution to $[d(P, Q)]^{2}$.

\section{Results}

\subsection{Occupational mobility over time}

Table 1 presents cross classification of son's occupation by father's occupation for son's birth cohorts 1945-1954 (panel 1), 1955-1964 (panel 2), 1965-74 (panel 3), and 1975-1984 (panel 4). For the son's birth cohort 1945-1954 (panel I, Table1), about 53.4 percentage of the sons born to white collar occupation fathers end up in white color jobs. This percentage gradually declined in later birth cohorts. For example, in birth cohort 1955-1964 (panel 2, Table 1), 43.0 percentage of sons born to white collar occupation fathers end up in white collar jobs; in birth cohort 1965$1974,44.4$ percentage of sons born to white color fathers end up in white collar jobs; and in most recent cohort born in 1975-1984, only 39.3 percentage of sons born to white collar fathers end up 
in white collar jobs. Thus, the persistence in transmission of white collar jobs from fathers to sons has declined over time.

However, among sons of skilled/semi-skilled and unskilled occupation fathers, the persistence in transmission of occupation to sons from fathers has increased. For example, the 62.7 percent of sons born during 1945-1954 to skilled/semi-skilled fathers ended up in the same occupation, whereas about 71.9 percent of sons born during 1975-1984 to skilled/semi-skilled fathers ended up in the same occupation. In addition, there is also less movement observed in recent cohorts to white collar jobs of sons who were born to skilled/semi-skilled workers. For example, 20.8 percent of sons born during 1945-54 to skilled/semi-skilled workers ended up in white collar jobs, whereas this percentage declined to 17.1 percent in birth cohort 1955-1964, to 14.7 percentage in birth cohort 1965-1974, and 10.0 percentage in birth cohort 1975-1984.

The persistence of occupation also exists in sons born to fathers with unskilled jobs, and this persistence has increased over time. Whereas the probability of someone born to unskilled fathers getting a white collar job has been declining, the probability of someone born to unskilled workers getting a skilled/semi-skilled job increased before experiencing a drop in the most recent cohort.

Over time the importance of farming has been declining in Indian economy, and movement into farming is increasingly seen not as a route to economic advancement. Only 43.9 percent of sons born during 1945-1954 to farmer fathers ended up working as farmer. This probably suggests movement out of agriculture from a very predominant farming society. The persistence of occupation to sons born to farmer fathers declined in sons born during 1945-1974, however, the persistence seems to have increased in recent cohort, which seems a little bit 
counterintuitive. However, the percentage of sons of farmers ending up with white collar or skilled/semi-skilled jobs has declined in recent cohort after increasing during 1945-1975. In addition, the percentage of sons of farmers ending up with unskilled jobs (includes agricultural laborers) increased in birth cohort 1955-1964, before decreasing in 1965-1974, and in birth cohort 1975-84. So, there is a possibility that sons born to farmer fathers in recent cohorts prefer staying in same occupation than moving to unskilled category, whereas getting a white collar job becoming more difficult for sons born to farmers. Sons of farmers born during 1975-1984 are two-third as likely to get a white collar job as sons born during 1945-1954 to farmer fathers.

In Table 2, we present the summary measures of mobility. Table 2 , panel 1 , column 1 shows the simple measure of total mobility $M$, and according to this the cohort born in 19451954 are more likely than the cohort born in 1955-1964 to find themselves in the occupations of their fathers. The mobility is 3.0 percentage points higher in the sons' cohort born during 195564 compared with sons' cohort born during 1945-54. However, the difference is mainly as a result of differences in occupational distributions. If the total mobility is measured using 1955-64 birth cohort occupation distributions, it is the 1945-54 birth cohort who have a 0.6 percentage points advantage in mobility compared with $1955-64$ birth cohort (53.7 vs. 53.1 ), not the $1955-$ 64 cohort as suggested by simple measure of mobility. The earlier cohort, 1945-54, also shows a higher mobility, by 0.9 percentage points using $1945-54$ occupation distributions (50.1 vs. 49.2).

The Altham statistics for the 1945-1954 birth cohort $(P)$ and 1955-1964 birth cohort $(Q)$ are: $d(P, I)=22.2$, and $d(Q, I)=21.9$, and both are significant at $1 \%$ significance level. Thus we can reject the null hypothesis that the association between rows and columns was the same as it would have under independence. In addition, these measures suggest that the association between fathers' and sons' occupations was slightly closer to independence (that is, it exhibited 
greater mobility) in the 1955-1964 birth cohort than in the 1945-1954 birth cohort, which is the opposite of what we got when we measured mobility adjusting for occupation distributions (we found marginal advantage for 1945-54 cohort). However, the difference between $P$ and $Q$ in their degree of association (panel 1, column 5, Table 2), $d(P, Q)$, is small in magnitude (3.2), and we cannot reject the null hypothesis that their associations are identical. Hence, we conclude that that the occupational mobility in 1955-64 cohort is more or less similar to the mobility observed in the 1945-1954 birth cohort. As we cannot reject the null of equal association in $P$ and $Q$ when we focus only on the off-diagonal elements (column 6, panel 1, Table 2), we conclude that the no difference in mobility in two cohorts is not solely because of strong similarities in tendency of sons to inherit their fathers occupations.

Table 2, panel 2 compares the mobility across birth cohort 1955-1964 $(P)$ and 1965-1974 $(Q)$. The simple mobility measure suggests that the mobility was higher in birth cohort 19651974 by 1.3 percentage points compared with the mobility observed in the birth cohort 19551964. If mobility is measured for both cohorts using either the 1955-64 cohort (53.1 vs. 53.4) or 1965-1974 cohort's (54.2 vs. 54.4) distributions of occupations, the advantage of 1965-74 cohort is 0.2 percentage points to 1.3 percentage points. The Altham statistics for the $1955-1964$ birth cohort $(P)$ and 1965-1974 birth cohorts are: $d(P, I)=21.9$, and $d(P, Q)=21.0$, and both are significant at $1 \%$ significance level. These measures suggest that the association between fathers' and sons' occupations was closer to independence in the 1965-1974 birth cohort than in the 1955-1964 birth cohort. However, $d(P, Q)=3.7$ is small, and we could not reject the null of equality of association between the matrices. Hence, we conclude that occupational mobility in 1955-64 birth cohort is more or less similar to the mobility observed in the 1965-1974 birth cohort. 
Table 2, panel 3, compares the mobility across birth cohort 1965-74 $(P)$ and most recent cohort 1975-1984 (Q). Simple measure of mobility suggests sharp decline in mobility between 1965-74 and 1975-84 birth cohorts: mobility declined by 7 percentage points. However, after adjusting distributions of occupations, if total mobility is measured using the 1965-74 cohort distribution of occupation, the observed decline in mobility falls from 7 percentage points to 0.7 percentage points (54.4 vs. 53.7) only. Similarly, if mobility is measured using 1975-84 occupation distribution, the gap in mobility falls from 7 percentage points to only 0.3 percentage points (47.7 vs. 47.4). The Altham statistics for the 1965-1974 birth cohort $(P)$ and 1975-1984 birth cohorts are: $d(P, I)=21.0$, and $d(Q, I)=20.8$, and both are significant at $1 \%$ significance level. In addition, $d(P, Q)=4.6$, and it's significant at $1 \%$ significance level. However, since $d(P, I) \approx d(Q, I)$, and $d(P, Q)>0$, tables $P$ and $Q$ have row-column associations that are equally distant from the row-column association observed under independence, but tables $P$ and $Q$ differ in how they differ from independence, i.e. the odds ratios in table $P$ that depart the most from independence are different from those that depart the most from independence in table $Q$.

Overall, there is no strong evidence in differences in mobility in successive ten year birth cohorts except between the 1965-74 and 1975-84 birth cohorts. However, the difference in 196574 and 1975-84 contingency tables are that they differ in how they differ from independence. Looking at longer period gap (panel 4, Table 2), between cohorts 1945-54 (P) and 1975-84 (Q), the simple measure of mobility suggests a decline in mobility by 2.7 percentage points. After adjusting for occupational differences, the mobility in the recent cohort is just 0.5 percentage points less (using 1945-54 occupation frequencies, 47.9 vs. 47.4 or using 1975-84 occupation frequencies, 50.1 vs. 49.6). Finally, if the two birth cohorts had swapped the occupational distributions and retained their underlying associations between fathers' and sons' occupations, 
the recent birth cohort (1975-1984) shows an advantage in mobility by 1.7 percentage points. Importantly, $d(Q, I)<d(P, I)$, and $d(P, Q) \neq 0$, the Altham Statistics suggest that the mobility in recent cohort is higher than the mobility in the 1945-54 birth cohort. Moreover, as we can reject the null of equal association even when the diagonal elements in $P$ and $Q$ are excluded, this suggests the difference is not driven by change in the likelihood of direct inheritance of the father's occupational status, but there are change in structure of association between two generations occupations.

As, we aggregated the 2-digit occupation categories into four groups which are much broader, it is important to know how our conclusions differs if we define occupation groups more finely. For this, we divided the occupations into nine groups based on 1-digit Indian National Classification of Occupations (NCO) classification. ${ }^{17}$ To preserve the space, we only provide the calculated summary measures in appendix Table A2, and do not report the transition tables. The magnitudes of the Altham statistics increased substantially for all cohorts; however, we cannot reject null of equal association between birth cohorts 1945-54 (P) and 1955-64 (Q), and between birth cohorts 1955-64 $(P)$ and 1965-74 $(Q)$. This is similar to what we found with four occupation categories. For birth cohorts 1965-74 (P) and 1975-84 (Q), we find that although $d(P, Q)>0$, but $d(P, I) \approx d(Q, I)$. Qualitatively this result is similar to results with four occupation categories: tables $\mathrm{P}$ and $\mathrm{Q}$ have row-column associations that are equally distant from the row-column association observed under independence, but tables $P$ and $Q$ differ in how they differ from independence. Looking at longer gap, for birth cohort 1945-54 $(P)$ and 1975-84 (Q), we find $d(P, I)=110.2>d(Q, I)=98.8$, and $d(P, Q)>0$, hence the mobility seems higher in the recent cohort. Thus the findings with nine occupation categories are broadly consistent with

\footnotetext{
17 The NCO is based upon the International Labour Organization (ILO) ISCO classification, suitably modified for the Indian conditions
} 
the findings with the four occupation categories, and we continue the rest of the analysis using the four occupation categories.

Table 3 presents the components which has contributed at least 5 percentage points in the difference between association in $P$ (1945-54 birth cohort) and $Q$ (1975-84 birth cohort). ${ }^{18}$ These components account for more than 90 percent of difference between associations. The first entry is the relative advantage in entering farming rather than unskilled work from having a skilled father rather than unskilled father. In recent cohort, 1975-84 birth cohort, sons of skilled fathers are 5.6 times more likely to enter farming rather than unskilled work than were the sons of unskilled fathers. In the 1945-54 cohort, the ratio was only 1.6 to one. Hence advantage of having a skilled father rather than unskilled father in making a move into farming rather than unskilled work is 3.5 times greater in 1975-84 cohort than in 1945-54 cohort. This odd ratio contrast account for 11.5 percent of the difference in association between $P$ and $Q$. The second entry also contributes 11.4 percent of the difference in association between $P$ and $Q$. It shows the relative advantage in entering farming rather than unskilled work from having a white collar father rather than an unskilled father. The odds ratio suggests that the relative advantage increased 2.9 times to 10.3 times between the two cohorts for such a move (moving to farming rather than to unskilled work) for sons with white collar father than sons with unskilled father. There seems also a decline in the disadvantage in entering white collar job rather than other jobs for sons of non-white collar fathers. For example, the third entry in Table 3 shows that the relative advantage in entering in white collar job rather than farming from having a skilled job father rather than having a unskilled job father declined from six times to two times. Similarly, the tenth entry in Table 3 shows that the relative advantage in entering in white collar job rather

\footnotetext{
${ }^{18} \mathrm{We}$ do not carry out the decomposition analysis for successive birth cohorts as the difference in association between sons and fathers' occupations between successive birth cohorts are not statistically significant.
} 
than farming from having a white collar father rather than having a unskilled job father declined from 11.6 times to 4.6 times. The 12 th entry shows that the relative advantage in entering in white collar job rather than farming from having a white collar father rather than having a farmer father declined from 45.3 times to 19.1 times.

\subsection{Occupational mobility among different social groups}

Although there exists many studies on Indian caste system, only few has tried to address intergenerational mobility issues. To answer the question of whether mobility differs across social groups, we re-ran our analysis for different social groups. However, to boost the cell size, this analysis is based of 20 year birth cohort rather than 10 year birth cohort. Table 4 provides cross classification of son's occupation by father's occupation for son's born during 1945-64 and 1965-84 for different social groups. Table 5 presents the summary measures of mobility. Based on simple measure of mobility (column (1) of Table 5), mobility among higher castes sons born during 1965-84 has been lower by 0.8 percentage points when compared with mobility among higher castes sons born during 1945-64. However, if we calculate mobility in both higher castes birth cohorts based on 1965-84 occupation distributions, mobility is marginally higher in the 1965-84 cohort (51.6 vs. 51.7). Similarly, based on the 1945-64 higher castes birth cohort's occupation distributions, the mobility in 1965-84 higher castes birth cohort is marginally higher. Moreover, the more fundamental measure of mobility, the Altham statistics, suggests that the 1965-84 higher castes birth cohort is closer to independence than the 1945-64 higher castes birth cohort. Also we can safely reject the null of equal association between the two higher castes cohorts. Since, $d(P, Q)>0$ and $d(P, I)>d(Q, I)$, we conclude the mobility is higher among the recent cohort for higher castes. 
For Scheduled Castes/Tribes, the simple measure of mobility suggests a decline in mobility in recent cohort (column 1, panel 2, Table 5) by 0.8 percentage points. However, once we take account of differences in occupation distributions, the recent cohort among SC/STs has about 2 percentage point advantage over the sons born during 1945-64 to SC/STs fathers. The Altham statistics also suggests that the row-column association is closer to independence among 1965-84 cohort than among the 1945-64 cohort. We also can reject the null of identical association among these two cohorts. As $d(P, Q)>0$, and $d(Q, I)<d(P, I)$, we conclude that the mobility among the recent SC/STs cohort is higher. More importantly, even we remove the diagonal elements, association off the diagonal elements differ across the two cohorts.

For OBCs, the simple measure again suggests a lower mobility (1.3 percentage points less) in recent cohort (panel 3, Table 5). Adjusting for occupation distribution reduces the gap in mobility; however, the recent cohort still has marginally less mobility. The Altham Statistics suggests $d(P, Q)>0$, and $d(P, I) \approx d(Q, I)$, which implies that tables (cohort 1945-64) $P$ and $Q$ (cohort 1965-84) have row-column associations that are equally distant from the row-column association observed under independence, but tables $P$ and $Q$ differ in how they differ from independence.

For Muslims, the simple measure suggests a lower mobility among recent cohort (panel 4, Table 5). Adjustments in occupation distributions reduce the disadvantage of recent cohort from about 2 percentage point to less than 1 percentage point. However, the Altham Statistics suggests that the row-column association in recent cohort is closer to independence than the rowcolumn association in birth cohort 1945-64. Nevertheless, we fail to reject identical associations in two cohorts, and conclude no changes in mobility. 
To summarize, the mobility in recent birth cohort (1965-84) has been higher (compared with the birth cohort 1945-64) for higher castes and SC/STs, whereas for Muslims, the mobility is not statistically different among the two cohorts.

Table 6 reports the components which have made at least 5 percent contribution in $[d(P, Q)]^{2}$. For higher castes, the two largest contributors in difference in son-father's occupation association between the birth cohort 1945-64 and 1965-84 suggest that relative advantage in entering farming rather than unskilled jobs from having a white collar/skilled father rather than having an unskilled job father increased in recent cohort. This is similar to the overall population story presented in the last section. For SCs/STs, the two important contributors suggest decline in advantage in entering white collar job rather than farming from having a white collar father rather than a farmer father; and increase in odds of getting white collar job rather than farming from having a farmer father rather than having a skilled job father. This suggests that the chance of upward mobility in recent SC/ST cohort is higher than the earliest cohort. In contrast, for OBCs, the relative advantage in entering white collar jobs rather than non-white collar jobs from having a white collar father rather than non-white collar father increased in recent cohort (entry 5, 7, 8 in the panel 3, Table 6).

\subsection{Does the mobility differ across social groups?}

The differences among social groups remain an important issue in India. We compare the differences among social groups in two ways. First, we compare mobility among each social group to total population mobility. Second, we compare mobility in different social groups to mobility among higher castes. Table 7 reports comparisons of mobility among each social group to mobility among entire population for two birth cohorts 1945-64 (panel I of Table 7) and 196584 (panel II of Table 7). For birth cohort 1945-64, although the simple measure of mobility 
suggests marginally higher (lower) mobility among higher castes and OBCs (SC/ST and Muslims) compared with the mobility in the entire population, we fail to reject the null of identical association among each group and population at conventional (5 percent) significance level. Hence for the birth cohort 1945-64, we find no evidence of difference in association between father and son's occupation in each social group to the association observed in the entire population.

Next we compare mobility for individuals born during 1965-84. The simple measure of mobility suggests that the mobility has been higher among higher castes compared to entire population by 0.9 percentage points (row 1, panel B, Table 7). After adjusting for differences in occupation distributions, the mobility advantage for higher castes remains (about 1 percentage points). As, $d(P, I)<d(Q, I)$, and $d(P, Q)>0$, the Altham statistics suggest that in birth cohort 1965-84, the mobility is higher among higher castes compared with mobility among entire population. Simple measure of mobility also suggests marginally higher mobility among SC/STs (0.2 percentage points) compared to the all in birth cohort 1965-84. The gap becomes larger after adjusting for occupational distributions. The SC/ST advantage increase to 2.3 percentage points if mobility is measured using the population occupation distribution (51.0 vs. 48.8), while the advantage is 2.6 percentage points using the SC/ST occupation distribution (53.4 vs. 50.8). The Altham Statistics also confirms a higher mobility among SC/STs compared to the entire population born during 1965-84.

For OBCs, the simple mobility measure shows 0.4 percentage points advantage in 196584 birth cohort (row 3, panel II, Table 7). Adjusting for occupation does not affect the gap. However, we fail to reject the null of equality of mobility among OBCs and entire population for 
birth cohort 1965-84. Hence, we conclude the mobility among OBCs born during 1965-84 is not very different from the mobility experienced by all who were born during 1965-84.

Similarly, the simple measure of mobility suggests a 3.7 percentage point disadvantage for Muslims born during 1965-84 compared to all who were born during the same period. However, after adjusting for occupational distributions the disadvantage in mobility turn out to be much smaller (less than 1 percentage point). Moreover, we fail to reject the null of equality of row-column associations in Muslims and all population at conventional level of significance.

Overall, for the birth cohort 1945-64, we do not find any evidence of difference in mobility among any social group when compared with the entire population; however, for the birth cohort 1965-84, we find higher mobility among higher castes and SC/STs than the mobility in entire population.

One may also be concerned about the difference between the disadvantaged social groups and the higher castes. To get these differences, we compare each social group with the higher castes. Table 8 provides comparisons of mobility among each social group to mobility among higher castes. For birth cohort 1945-64 (panel 1 of Table 8), we fail to reject the null of identical associations between $\mathrm{OBCs}$ or Muslims and higher castes. However, we can safely reject identical association among SC/STs and higher castes. The simple measure of mobility suggest 0.7 percentage point disadvantage for SC/STs when compared with the higher castes. This disadvantage increases once we adjust for occupations (50.7 vs. 52.5 or 51.8 vs. 52.5 ). As $d(P, I)>d(Q, I)$, and $d(P, Q)>0$, the association between fathers and sons occupation differed from independence more among SC/STs than among the higher castes. Hence, we 
conclude that the mobility among SC/STs was lower than mobility among higher castes in birth cohort 1945-64.

For birth cohort 1965-84 (panel 2, Table 8), the simple measure of mobility suggests that the mobility among SC/STs is lower than mobility among higher castes by 0.7 percentage points. However, the disadvantage of SC/STs turns out to be advantage from 1.2 (51.0 vs. 49.8) to 1.7 (53.4 vs. 51.7) percentage points after adjustment of occupational distributions. The more fundamental measure of association $d(P, I)$ and $d(Q, I)$ also shows a weaker association (more mobility) among SC/STs compared with the higher castes. As $d(P, Q)>0$, and $d(P, I)<$ $d(Q, I)$, we conclude that the mobility among SC/STs is higher than the mobility among higher castes in birth cohort 1965-84. However, we fail to reject the equality of association between Muslims and higher castes at conventional level of significance. The simple measure of mobility suggest slight disadvantage for OBCs compared to higher castes. The slight disadvantage for OBCs persists even after adjusting for occupation distributions. Moreover, we reject the null of equality of association between $\mathrm{OBCs}$ and higher castes. As $d(P, Q)>0$, and $d(P, I) \approx d(Q, I)$, we conclude the $\mathrm{OBCs}$ and higher castes have row-column associations that are equally distant from the row-column association observed under independence, but associations among OBCs and higher castes differ in how they differ from independence.

Table 9 reports the components which have largest contribution in difference in association between SC/STs and higher castes. Panel 1 of Table 9 reports this for 1945-64 birth cohort. The first two entries contribute almost 23 percent of the differences. The first entry is relative advantage of entering into white collar job than farming from having a white collar father than a skilled occupation father. The relative advantage is 2.6 times among SC/STs while it is only 0.9 times among higher castes. The second entry is relative advantage of entering into 
white collar job than unskilled job from having a white collar father than an unskilled father. The relative advantage is 38.4 times among SC/STs compared with 15.4 times among higher castes. Of the thirteen odd ratios that account for more than 75 percent of difference among SC/STs and higher castes, eight displays a higher advantage in entering white collar job for sons of white collar fathers among SC/STs than among higher castes.

For birth cohort 1965-84 (panel 2, Table 9), the highest contributor to the difference between SC/STs and higher castes suggest that the odds of entering in white collar job rather than farming from having a farmer father than skilled occupation father is two times higher among SC/STs when compared with the higher castes. Similarly, the third entry suggest that relative advantage in entering white collar job rather than unskilled job from having skilled job father rather than having an unskilled father is less in SC/STs than higher castes (1.5 times vs. 4.2 times).

The difference in mobility based on geographical dimensions, such as urban/rural or states remains an important question. However, we only know the area of residence at the time of survey, and due to urbanization (or migration) over time more areas might have been classified as urban making it difficult to compare mobility across cohorts by urban/rural residence. In addition, we do not have enough sample sizes to do our analysis over time by states. Hence, we do not attempt to examine differences in mobility across geographical dimensions.

\section{Conclusion}

In this paper, we address the issue of occupation-specific human capital transmission between fathers and sons in India spanning birth cohorts from 1945 to 1984 . We are able to find fathers' occupation information for majority of adult males surveyed in the nationally 
representative India Human Development Survey (IHDS). In addition, we also examine the differential in mobility across social groups.

We find that the simple measure of mobility (fraction of sons who end up in jobs different from those of their fathers) provide an incomplete picture in changing economy. Many of the findings based on simple measure of mobility are reversed once we adjust for differences in marginal distributions of occupations to disentangle the true association between father-son occupations. Using the Altham statistics which provides a more robust measure of distance (Long and Ferrie, 2013, 2007; Altham and Ferrie, 2008; and Ferrie, 2005) between the associations of son-father occupations across cohorts/groups, we find no strong evidence in differences in mobility in successive ten year birth cohorts except between the 1965-74 and 1975-84 birth cohorts. Moreover, the 1965-74 and 1975-84 birth cohorts differ in how they differ from independence, i.e. the odds ratios---for example, the odds that the son of a white collar father would get a white collar job compared with the odds that the son of a low-skilled father would get a white collar job---in the birth cohort 1965-74 that depart the most from independence (odds ratio of one) are different from those that depart the most from independence in the birth cohort 1975-84. Interesting, these two birth cohorts are likely to have entered in labor market in the late 1980s and 1990s, which saw a dramatic shift in Indian economic policy from a closed economy to increasingly globalized economy following the liberalization introduced in May, 1991. In this paper, we haven't tried to assess the importance of the shift in the economic policy in affecting the intergenerational occupation mobility; however, we believe that this remains an important direction of future work.

We also find that the mobility among higher castes and SC/STs has been higher in birth cohort 1965-84 when compared with the 1945-64 birth cohort. Moreover, although SC/STs had a 
lower mobility compared with higher castes in birth cohort 1945-64; they experienced a higher mobility compared with the higher castes in the 1965-84 birth cohort. SC/STs have been beneficiaries of the affirmative action policy under which a quota of places, in higher education and in government jobs, has been reserved for them. If the caste system (as it is widely believed) trapped many potentially talented people at the lower levels of the society, then the affirmative policy potentially could lead to a period of social mobility among SC/STs. Although we document improvement in mobility in SC/STs over time and compared with the higher castes, we do not attempt to assess whether the improvement in mobility among SC/STs are a result of the affirmative policy. However, we believe that our work will provide foundations for any future work in these directions. 


\section{References}

Agresti, A (2002), Categorical Data Analysis, New York: Wiley-Interscience.

Altham, P.M.E and Ferrie, J.P. (2007), Comparing Contingency Tables: Tools for Analyzing

Data from Two Groups Cross-Classified by two Characteristics, Historical Methods, 40(1), 3-16.

Azam, M and Bhatt, V. (2012), Like Father, Like Son? Intergenerational Educational Mobility in India, IZA Discussion Paper, 6549.

Black, S. E and Devereux, P. J. (2010), Recent developments in intergenerational mobility, National Bureau of Economic Research Working Paper Series, No. 15889.

Blanden, J. (2009), How Much Can We Learn From International Comparisons Of Intergenerational Mobility?, Centre for the Economics of Education DP, 111, London School of Economics.

Björklund, A and Jäntti, M. (2000), Intergenerational mobility of socio-economic status in comparative perspective, Nordic Journal of Political Economy, 26, 3-33.

Bourdieu, J., Ferrie, J., and Kesztenbaum, L. (2006), Vive la différence? Intergenerational Occupational Mobility in France and the U.S. in the 19th and 20th Centuries, available at http://mauricio.econ.ubc.ca/pdfs/ferrie.pdf

Breen, R. (2004), Social Mobility in Europe, Oxford University Press.

Desai, S. B., Dubey, A., Joshi, B. L., Sen, M., Shariff, A., and Vanneman, R. ( 2010), Human Development in India: Challenges for a Society in Transition, Oxford University Press.

Despande, A. (2000), Does Caste Still Define Disparity? A Look at Inequality in Kerala, India, American Economic Review Papers and Proceedings, 90(2), 322-25.

DiPrete, T. A. and Grusky, D.B. (1990), Structure and Trend in the Process of Stratification for American Men and Women, American Journal of Sociology, 96(1), 107-43.

Erikson, R. \& Goldthorpe, J. H. (1992), The Constant Flux - A Study of Class Mobility in Industrial Societies, Clarendon, Oxford, England.

Ferrie, J.P. (2005), History Lessons: The End of American Exceptionalism? Mobility in the United States Since 1850, Journal of Economic Perspectives, 19( 3), 199-215.

Ganzeboom, H. B. G. and Treiman, D. J. (1996), Internationally Comparable Measures of Occupational Status for the 1988 International Standard Classification of Occupations, Social Science Research, 25 (2): 201-39. 
Hellerstein, J.K and and Morrill, M.S. (2011), Dads and Daughters: The Changing Impact of Fathers on Women's Occupational Choices, Journal of Human Resources, ,46, 333-372.

Hnatkovskay, V., Lahiri, A. and Paul S.B. (2013), Breaking the Caste Barrier: Intergenerational Mobility in India, Journal of Human Resources, 48(2), 435-73.

Jäntti, M., Bratsberg, .B., Røed, K., Raaum, O., Naylor, R., Österbacka, E., Björklund, A. and Eriksson, T. (2006). American Exceptionalism in a New Light: A Comparison of Intergenerational Earnings Mobility in the Nordic countries, the United Kingdom and the United States, IZA Discussion Paper, 1938.

Long, J and Ferrie, J. (2013), Intergenerational Occupational Mobility in Britain and the U.S. Since 1850, American Economic Review, 103(4): 1109-37.

Long, J and Ferrie, J. (2007), The Path to Convergence: Intergenerational Occupational Mobilty in Britain and the US in Three Eras, Economic Journal, C61-C71.

Maasoumi, E. (1997), On mobility, In: Giles, D. and Ullah,A. (Eds.), The Handbook of Economic Statistics, Marcel Dekker, New York.

Majumder, R. (2010). Intergenerational Mobility in Educational and Occupational Attainment: A Comparative Study of Social Classes in India, Margin-The Journal of Applied Economic Research, 4 (4): 463-494.

Manski, C. (1995), Identification Problems in the Social Sciences, Cambridge, MA: Harvard University Press

Motoram, S and Singh, A. (2012), How Close Does the Apple Fall to the Tree? Some Evidence on Intergenerational Occupational Mobility from India, Economic and Political Weekly, Vol XLVII No. 40.

Munshi, K. and Rosenzweig, M. (2009), Why is Mobility in India so Low? Social Insurance, Inequality, and Growth?, NBER Working Paper, 14850

Xie, Y.and Killewald, A. (2013), Intergenerational Occupational Mobility in Britain and the US since 1850: Comment, forthcoming in American Economic Review. 
Table 1: Intergenerational Occupational Mobility in India, 1945-1984 birth cohorts

\begin{tabular}{|c|c|c|c|c|c|c|c|c|c|c|c|}
\hline \multicolumn{6}{|c|}{ Panel 1: Son's Birth Cohort=1945-1954 } & \multicolumn{6}{|c|}{ Panel 3: Son's Birth Cohort=1965-1974 } \\
\hline & \multicolumn{5}{|c|}{ Father's Occupation } & & \multicolumn{5}{|c|}{ Father's Occupation } \\
\hline Son's occupation & $\begin{array}{l}\text { White } \\
\text { Collar }\end{array}$ & $\begin{array}{l}\text { Skilled/Semi- } \\
\text { skilled }\end{array}$ & Unskilled & Farmers & $\begin{array}{l}\text { Row } \\
\text { Sum }\end{array}$ & Son's occupation & $\begin{array}{l}\text { White } \\
\text { collar }\end{array}$ & $\begin{array}{c}\text { Skilled/Semi- } \\
\text { skilled }\end{array}$ & Unskilled & Farmers & $\begin{array}{l}\text { Row } \\
\text { Sum }\end{array}$ \\
\hline \multirow[t]{2}{*}{ White Collar } & 132 & 220 & 129 & 278 & 759 & White Collar & 294 & 361 & 224 & 500 & 1,379 \\
\hline & $(53.4)$ & $(20.8)$ & (8.9) & $(9.1)$ & $(13.1)$ & & $(44.4)$ & $(14.7)$ & $(7.2)$ & $(9.8)$ & (12.1) \\
\hline Skilled/Semi-Skilled & (31.6) & $(62.7)$ & $(27.3)$ & (21.7) & $(31.0)$ & & (39.9) & (71.6) & (32.5) & (30.9) & (40.7) \\
\hline \multirow[t]{2}{*}{ Unskilled } & 23 & 131 & 764 & 773 & 1,691 & Unskilled & 66 & 278 & 1,711 & 1,639 & 3,694 \\
\hline & (9.3) & $(12.4)$ & (52.8) & $(25.3)$ & (29.1) & & $(10.0)$ & (11.3) & $(55.2)$ & (31.9) & (32.5) \\
\hline \multirow[t]{2}{*}{ Farmers } & 14 & 43 & 159 & 1,337 & 1,553 & Farmers & 38 & 59 & 155 & 1,414 & 1,666 \\
\hline & $(5.7)$ & $(4.1)$ & $(11.0)$ & (43.9) & $(26.8)$ & & (5.8) & $(2.4)$ & $(5.0)$ & $(27.5)$ & (14.7) \\
\hline Column sum & 247 & 1,057 & 1,446 & 3,048 & 5,798 & Column sum & 662 & 2,456 & 3,098 & 5,141 & 11,357 \\
\hline \multicolumn{6}{|c|}{ Panel 2: Son's Birth Cohort=1955-1964 } & \multicolumn{6}{|c|}{ Panel 4: Son's Birth Cohort=1975-1984 } \\
\hline & \multicolumn{5}{|c|}{ Father's Occupation } & & \multicolumn{5}{|c|}{ Father's Occupation } \\
\hline Son's occupation & $\begin{array}{l}\text { White } \\
\text { collar }\end{array}$ & $\begin{array}{l}\text { Skilled/Semi- } \\
\text { skilled }\end{array}$ & Unskilled & Farmers & $\begin{array}{l}\text { Row } \\
\text { Sum }\end{array}$ & Son's occupation & $\begin{array}{l}\text { White } \\
\text { collar }\end{array}$ & $\begin{array}{l}\text { Skilled/Semi- } \\
\text { skilled }\end{array}$ & Unskilled & Farmers & $\begin{array}{l}\text { Row } \\
\text { Sum }\end{array}$ \\
\hline \multirow[t]{2}{*}{ White Collar } & 198 & 313 & 226 & 409 & 1,146 & White Collar & 307 & 301 & 175 & 299 & 1,082 \\
\hline & $(43.0)$ & $(17.1)$ & $(9.1)$ & $(9.4)$ & $(12.6)$ & & (39.3) & $(10.0)$ & (4.9) & $(6.4)$ & (9.0) \\
\hline \multirow[t]{2}{*}{ Skilled/Semi-Skilled } & 190 & 1,286 & 764 & 1,180 & 3,420 & Skilled/Semi-Skilled & 302 & 2,167 & 1,059 & 1,326 & 4,854 \\
\hline & $(41.2)$ & $(70.2)$ & $(30.8)$ & (27.3) & $(37.6)$ & & (38.7) & (71.9) & $(29.6)$ & (28.4) & (40.3) \\
\hline \multirow[t]{2}{*}{ Unskilled } & 51 & 195 & 1,347 & 1,307 & 2,900 & Unskilled & 77 & 328 & 2,089 & 1,273 & 3,767 \\
\hline & (11.1) & $(10.7)$ & $(54.3)$ & $(30.2)$ & (31.9) & & (9.9) & (10.9) & (58.5) & (27.3) & (31.3) \\
\hline \multirow[t]{2}{*}{ Farmers } & 22 & 37 & 144 & 1,435 & 1,638 & Farmers & 95 & 219 & 250 & 1,766 & 2,330 \\
\hline & $(4.8)$ & (2.0) & $(5.8)$ & (33.1) & $(18.0)$ & & $(12.2)$ & $(7.3)$ & $(7.0)$ & (37.9) & (19.4) \\
\hline Column sum & 461 & 1,831 & 2,481 & 4,331 & 9,104 & Column sum & 781 & 3,015 & 3,573 & 4,664 & 12,033 \\
\hline
\end{tabular}

Note: the numbers in parenthesis are percentage of column sum. 
Table 2: Summary Measures of Mobility

\begin{tabular}{lcccccc}
\hline \hline & $\mathrm{M}$ & $\mathrm{M}^{\prime}$ & $\mathrm{d}(\mathrm{P}, \mathrm{I})$ & $\mathrm{d}(\mathrm{Q}, \mathrm{I})$ & $\mathrm{d}(\mathrm{P}, \mathrm{Q})$ & $\mathrm{d}^{\mathrm{i}}(\mathrm{P}, \mathrm{Q})$ \\
& $(1)$ & $(2)$ & $(3)$ & $(4)$ & $(5)$ & $(6)$ \\
\hline 1. Cohort 1945-1954 (P) & 50.1 & 53.7 & $22.2^{* * *}$ & & 3.2 & 1.7 \\
vs. Cohort 1955-1964 (Q) & 53.1 & 49.2 & & $21.9^{* * *}$ & & \\
& & & & & & \\
2. Cohort 1955-1964 (P) & 53.1 & 54.2 & $21.9^{* * *}$ & & 3.7 & 2.0 \\
vs. Cohort 1965-1974 (Q) & 54.4 & 53.4 & & $21.0^{* * *}$ & & \\
& & & & & & \\
3. Cohort 1965-1974 (P) & 54.4 & 47.7 & $21.0^{* * *}$ & & $4.6^{* * *}$ & $3.3^{* *}$ \\
vs. Cohort 1975-1984 (Q) & 47.4 & 53.7 & & $20.8^{* * *}$ & & \\
& & & & & \\
4. Cohort 1945-1954 (P) & $\mathbf{5 0 . 1}$ & $\mathbf{4 7 . 9}$ & $\mathbf{2 2 . 2 * * *}$ & & $\mathbf{7 . 5 * * *}$ & $\mathbf{5 . 8 * * *}$ \\
vs. Cohort 1975-1984 (Q) & $\mathbf{4 7 . 4}$ & $\mathbf{4 9 . 6}$ & & $\mathbf{2 0 . 8 * * *}$ & & \\
\hline \hline
\end{tabular}

Note: $M$ is total mobility (percent off the main diagonal), $M^{\prime}$ is total mobility using the marginal frequencies from the $Q$ matrix. Significance levels for the likelihood ratio $\chi^{2}$ statistic $G^{2}$ (d.f. 9 for $d(P, I), d(Q, I)$, and $d(P, Q) ; 5$ for di $(P, Q)$ ): $* * *<0.01 * *<0.05 *<0.10$. 
Table 3: Components of $d(P, I), d(Q, I)$, and $d(P, Q)$ for sons' birth cohort 1945-54 (P) vs. birth cohort 1975-84 (Q)

\begin{tabular}{|c|c|c|c|c|c|c|c|}
\hline Contrast & $d(P, I)$ & $\begin{array}{l}\text { Odds } \\
\text { ratio }\end{array}$ & $\mathrm{d}(\mathrm{Q}, \mathrm{I})$ & $\begin{array}{l}\text { Odds } \\
\text { ratio }\end{array}$ & $d(P, Q)$ & $\begin{array}{c}\text { Percentage } \\
\text { of total }\end{array}$ & $\begin{array}{l}\text { Cumulative } \\
\text { percentage }\end{array}$ \\
\hline 1. $[(\mathrm{SF}) /(\mathrm{SU})] /[(\mathrm{UF}) /(\mathrm{UU})]$ & $0.91 * * *$ & 1.58 & $3.4^{* * *}$ & 5.58 & $2.53 * * *$ & 11.47 & 11.47 \\
\hline 2. $[(\mathrm{WF}) /(\mathrm{WU})] /[(\mathrm{UF}) /(\mathrm{UU})]$ & $2.15^{* * *}$ & 2.92 & $4.7 * * *$ & 10.31 & $2.52 * * *$ & 11.41 & 22.88 \\
\hline 3. $[(S W) /(S F)] /[(U W) /(U F)]$ & $3.68 * * *$ & 6.31 & $1.3^{* * *}$ & 1.96 & $2.33^{* * *}$ & 9.79 & 32.67 \\
\hline 4. $[(\mathrm{FW}) /(\mathrm{FF})] /[(\mathrm{SW}) /(\mathrm{SF})]$ & $6.41 * * *$ & 0.04 & $4.2^{* * *}$ & 0.12 & $2.22 * * *$ & 8.84 & 41.51 \\
\hline 5. $[(W F) /(W S)] /[(U F) /(U S)]$ & $1.62 * * *$ & 0.44 & $0.6 * * *$ & 1.33 & $2.19 * * *$ & 8.65 & 50.16 \\
\hline 6. $[(\mathrm{WF}) /(\mathrm{WS})] /[(\mathrm{FF}) /(\mathrm{FS})]$ & $4.85 * * *$ & 0.09 & $2.9 * * *$ & 0.24 & $1.96 * * *$ & 6.91 & 57.07 \\
\hline 7. $[(\mathrm{SF}) /(\mathrm{SS})] /[(\mathrm{UF}) /(\mathrm{US})]$ & $3.66 * * *$ & 0.16 & $1.7^{* * *}$ & 0.43 & $1.96 * * *$ & 6.90 & 63.97 \\
\hline 8. $[(\mathrm{FF}) /(\mathrm{FU})] /[(\mathrm{SF}) /(\mathrm{SU})]$ & $3.32 * * *$ & 5.27 & $1.5^{* * *}$ & 2.08 & $1.86 * * *$ & 6.23 & 70.20 \\
\hline 9. $[(\mathrm{WF}) /(\mathrm{WU})] /[(\mathrm{FF}) /(\mathrm{FU})]$ & $2.09 * * *$ & 0.35 & 0.2 & 0.89 & $1.85^{* * *}$ & 6.18 & 76.38 \\
\hline 10. $[(\mathrm{WW}) /(\mathrm{WF})] /[(\mathrm{UW}) /(\mathrm{UF})]$ & $4.91 * * *$ & 11.62 & $3.1^{* * *}$ & 4.62 & $1.85^{* * *}$ & 6.13 & 82.50 \\
\hline 11. $[(\mathrm{WW}) /(\mathrm{WF})] /[(\mathrm{FW}) /(\mathrm{FF})]$ & $7.63 * * *$ & 45.35 & $5.9 * * *$ & 19.09 & $1.73 * * *$ & 5.38 & 87.88 \\
\hline 12. $[(\mathrm{FF}) /(\mathrm{FS})] /[(\mathrm{SF}) /(\mathrm{SS})]$ & $6.88 * * *$ & 31.23 & $5.2 * * *$ & 13.18 & $1.73 * * *$ & 5.35 & 93.24 \\
\hline
\end{tabular}

Notes: First element of each pair is father's occupation, second is son's. W: White Collar, S: Skilled/Semiskilled, U: Unskilled, F: Farmer. Significance levels for the likelihood ratio $\chi^{2}$ statistic $G^{2}$.

$* * *<0.01 * *<0.05 *<0.10$. 
Table 4: Transition matrices for social groups

\begin{tabular}{|c|c|c|c|c|c|c|c|c|c|c|c|}
\hline \multicolumn{6}{|l|}{ Panel 1: Higher castes } & \multicolumn{6}{|c|}{ Panel 2: Other Backward Castes } \\
\hline \multicolumn{2}{|c|}{ Son's Birth Cohort=1945-1964 } & \multirow[b]{2}{*}{$\begin{array}{l}\text { Skilled/semi- } \\
\text { skilled }\end{array}$} & \multirow[b]{2}{*}{ Unskilled } & \multirow[b]{2}{*}{ Farmers } & \multirow[b]{2}{*}{$\begin{array}{l}\text { Row } \\
\text { sum }\end{array}$} & \multicolumn{2}{|c|}{ Son's Birth Cohort=1945-1964 } & \multirow[b]{2}{*}{$\begin{array}{c}\text { Skilled/semi- } \\
\text { skilled }\end{array}$} & \multirow[b]{2}{*}{ Unskilled } & \multirow[b]{2}{*}{ Farmers } & \multirow[b]{2}{*}{$\begin{array}{l}\text { Row } \\
\text { sum }\end{array}$} \\
\hline & $\begin{array}{l}\text { White } \\
\text { Collar }\end{array}$ & & & & & & $\begin{array}{l}\text { White } \\
\text { Collar }\end{array}$ & & & & \\
\hline \multirow[t]{2}{*}{ White Collar } & 201 & 223 & 114 & 282 & 820 & White Collar & 57 & 150 & 115 & 245 & 567 \\
\hline & (51.9) & $(23.2)$ & $(15.7)$ & $(13.3)$ & $(19.5)$ & & (34.3) & $(17.0)$ & (9.2) & $(8.4)$ & $(10.9)$ \\
\hline \multirow[t]{2}{*}{ Skilled/Semi-Skilled } & 138 & 647 & 267 & 542 & 1,594 & Skilled/Semi-Skilled & 73 & 595 & 389 & 666 & 1,723 \\
\hline & $(35.7)$ & $(67.2)$ & $(36.7)$ & $(25.5)$ & (37.9) & & $(44.0)$ & $(67.2)$ & (31.1) & $(22.8)$ & $(33.0)$ \\
\hline \multirow[t]{2}{*}{ Unskilled } & 29 & 73 & 254 & 405 & 761 & Unskilled & 24 & 109 & 637 & 817 & 1,587 \\
\hline & (7.5) & $(7.6)$ & (34.9) & (19.1) & $(18.1)$ & & $(14.5)$ & $(12.3)$ & $(51.0)$ & $(28.0)$ & $(30.4)$ \\
\hline \multirow[t]{2}{*}{ Farmers } & 19 & 20 & 93 & 895 & 1,027 & Farmers & 12 & 31 & 109 & 1,195 & 1,347 \\
\hline & (4.9) & $(2.1)$ & $(12.8)$ & $(42.1)$ & $(24.4)$ & & $(7.2)$ & $(3.5)$ & (8.7) & $(40.9)$ & $(25.8)$ \\
\hline Column sum & 387 & 963 & 728 & 2,124 & 4,202 & Column sum & 166 & 885 & 1,250 & 2,923 & 5,224 \\
\hline \multicolumn{2}{|c|}{ Son's Birth Cohort=1965-1984 } & & & & & \multicolumn{2}{|c|}{ Son's Birth Cohort=1965-1984 } & & & & \\
\hline & $\begin{array}{l}\text { White } \\
\text { Collar }\end{array}$ & $\begin{array}{l}\text { Skilled/semi- } \\
\text { skilled }\end{array}$ & Unskilled & Farmers & $\begin{array}{l}\text { Row } \\
\text { sum }\end{array}$ & & $\begin{array}{l}\text { White } \\
\text { Collar }\end{array}$ & $\begin{array}{l}\text { Skilled/semi- } \\
\text { skilled }\end{array}$ & Unskilled & Farmers & $\begin{array}{l}\text { Row } \\
\text { sum }\end{array}$ \\
\hline \multirow[t]{2}{*}{ White Collar } & 274 & 263 & 116 & 301 & 954 & White Collar & 173 & 203 & 128 & 280 & 784 \\
\hline & $(45.7)$ & $(18.2)$ & (11.1) & (11.1) & $(16.4)$ & & $(40.7)$ & $(11.7)$ & (6.2) & (7.1) & (9.6) \\
\hline \multirow[t]{2}{*}{ Skilled/Semi-Skilled } & 234 & 1,007 & 370 & 804 & 2,415 & Skilled/Semi-Skilled & 158 & 1,235 & 621 & 1,108 & 3,122 \\
\hline & $(39.0)$ & (69.7) & $(35.4)$ & $(29.5)$ & $(41.5)$ & & (37.2) & (70.9) & $(30.2)$ & $(28.2)$ & (38.3) \\
\hline \multirow[t]{2}{*}{ Unskilled } & 37 & 113 & 442 & 535 & 1,127 & Unskilled & 51 & 187 & 1,150 & 1,120 & 2,508 \\
\hline & (6.2) & $(7.8)$ & $(42.3)$ & (19.6) & (19.4) & & $(12.0)$ & $(10.7)$ & (55.9) & $(28.5)$ & (30.8) \\
\hline \multirow[t]{2}{*}{ Farmers } & 55 & 62 & 116 & 1,085 & 1,318 & Farmers & 43 & 116 & 157 & 1,418 & 1,734 \\
\hline & (9.2) & $(4.3)$ & (11.1) & $(39.8)$ & $(22.7)$ & & (10.1) & (6.7) & (7.6) & (36.1) & $(21.3)$ \\
\hline Column sum & 600 & 1,445 & 1,044 & 2,725 & 5,814 & Total & 425 & 1,741 & 2,056 & 3,926 & 8,148 \\
\hline
\end{tabular}

Note: the numbers in parenthesis are percentage of column sum. 
Table 4 (cont'd): Transition matrices for social groups

\begin{tabular}{|c|c|c|c|c|c|c|c|c|c|c|c|}
\hline \multicolumn{6}{|c|}{ Panel 3: Scheduled Castes/Scheduled Tribes } & \multicolumn{6}{|l|}{ Panel 4: Muslims } \\
\hline \multicolumn{2}{|c|}{ Son's Birth Cohort=1945-1964 } & \multirow[b]{2}{*}{$\begin{array}{c}\text { Skilled/ } \\
\text { semi-skilled }\end{array}$} & \multirow[b]{2}{*}{ Unskilled } & \multirow[b]{2}{*}{ Farmers } & \multirow[b]{2}{*}{$\begin{array}{l}\text { Row } \\
\text { sum }\end{array}$} & \multicolumn{2}{|c|}{ Son's Birth Cohort=1945-1964 } & \multirow[b]{2}{*}{$\begin{array}{c}\text { Skilled/ } \\
\text { semi-skilled }\end{array}$} & \multirow[b]{2}{*}{ Unskilled } & \multirow[b]{2}{*}{ Farmers } & \multirow[b]{2}{*}{$\begin{array}{l}\text { Row } \\
\text { sum }\end{array}$} \\
\hline & $\begin{array}{l}\text { White } \\
\text { Collar }\end{array}$ & & & & & & $\begin{array}{l}\text { White } \\
\text { Collar }\end{array}$ & & & & \\
\hline \multirow[t]{2}{*}{ White Collar } & 47 & 77 & 80 & 116 & 320 & White Collar & 25 & 83 & 46 & 44 & 198 \\
\hline & $(46.1)$ & $(14.0)$ & (5.1) & $(6.5)$ & (8.0) & & $(47.2)$ & (16.9) & $(11.8)$ & (7.9) & $(13.3)$ \\
\hline \multirow[t]{2}{*}{ Skilled/Semi-Skilled } & 36 & 358 & 357 & 473 & 1,224 & Skilled/Semi-Skilled & 21 & 349 & 145 & 159 & 674 \\
\hline & $(35.3)$ & $(65.2)$ & (22.9) & $(26.6)$ & $(30.7)$ & & (39.6) & (71.1) & (37.1) & $(28.7)$ & $(45.2)$ \\
\hline \multirow[t]{2}{*}{ Unskilled } & 16 & 101 & 1,046 & 718 & 1,881 & Unskilled & 5 & 43 & 174 & 140 & 362 \\
\hline & $(15.7)$ & (18.4) & $(67.1)$ & $(40.4)$ & $(47.2)$ & & (9.4) & (8.8) & (44.5) & $(25.2)$ & $(24.3)$ \\
\hline \multirow[t]{2}{*}{ Farmers } & 3 & 13 & 75 & 470 & 561 & Farmers & 2 & 16 & 26 & 212 & 256 \\
\hline & (2.9) & (2.4) & $(4.8)$ & $(26.5)$ & $(14.1)$ & & (3.8) & (3.3) & (6.7) & $(38.2)$ & $(17.2)$ \\
\hline Column sum & 102 & 549 & 1,558 & 1,777 & 3,986 & Column sum & 53 & 491 & 391 & 555 & 1,490 \\
\hline \multicolumn{2}{|c|}{ Son's Birth Cohort=1965-1984 } & & & & & \multicolumn{2}{|c|}{ Son's Birth Cohort=1965-1984 } & & & & \\
\hline & $\begin{array}{l}\text { White } \\
\text { Collar }\end{array}$ & $\begin{array}{c}\text { Skilled/ } \\
\text { semi-skilled }\end{array}$ & Unskilled & Farmers & $\begin{array}{l}\text { Row } \\
\text { sum }\end{array}$ & & $\begin{array}{l}\text { White } \\
\text { Collar }\end{array}$ & $\begin{array}{c}\text { Skilled/ } \\
\text { semi-skilled }\end{array}$ & Unskilled & Farmers & $\begin{array}{l}\text { Row } \\
\text { sum }\end{array}$ \\
\hline \multirow[t]{2}{*}{ White Collar } & 80 & 104 & 108 & 142 & 434 & White Collar & 74 & 92 & 47 & 76 & 289 \\
\hline & (34.3) & $(8.2)$ & (3.6) & (6.1) & (6.4) & & $(40.0)$ & (9.1) & (7.8) & (9.2) & (11.0) \\
\hline \multirow[t]{2}{*}{ Skilled/Semi-Skilled } & 95 & 877 & 825 & 709 & 2,506 & Skilled/Semi-Skilled & 79 & 806 & 251 & 293 & 1,429 \\
\hline & $(40.8)$ & (68.9) & $(27.8)$ & $(30.5)$ & $(36.8)$ & & $(42.7)$ & (79.6) & (41.7) & (35.4) & $(54.4)$ \\
\hline \multirow[t]{2}{*}{ Unskilled } & 38 & 224 & 1,931 & 1,030 & 3,223 & Unskilled & 17 & 82 & 277 & 227 & 603 \\
\hline & (16.3) & (17.6) & (65.0) & (44.3) & $(47.4)$ & & $(9.2)$ & (8.1) & (46.0) & $(27.5)$ & $(23.0)$ \\
\hline \multirow[t]{2}{*}{ Farmers } & 20 & 68 & 105 & 446 & 639 & Farmers & 15 & 32 & 27 & 231 & 305 \\
\hline & (8.6) & (5.3) & (3.5) & (19.2) & (9.4) & & (8.1) & (3.2) & $(4.5)$ & (27.9) & (11.6) \\
\hline Column sum & 233 & 1,273 & 2,969 & 2,327 & 6,802 & Column sum & 185 & 1,012 & 602 & 827 & 2,626 \\
\hline
\end{tabular}

Note: the numbers in parenthesis are percentage of column sum. 
Table 5: Mobility measures across cohorts for different social groups

\begin{tabular}{|c|c|c|c|c|c|c|c|}
\hline & & $\begin{array}{l}M \\
(1) \\
\end{array}$ & $\begin{array}{l}M^{\prime} \\
(2)\end{array}$ & $\begin{array}{c}d(\mathbf{P}, \mathrm{I}) \\
(3)\end{array}$ & $\begin{array}{c}d(Q, I) \\
(4)\end{array}$ & $\begin{array}{c}d(P, Q) \\
(5)\end{array}$ & $\begin{array}{c}d^{i}(P, Q) \\
(6)\end{array}$ \\
\hline \multirow[t]{2}{*}{ 1. Higher castes } & 1. Cohort 1945-1964 (P) & 52.5 & 51.6 & $21.6 * * *$ & & $6.2^{* * *}$ & 3.8 \\
\hline & vs. Cohort 1965-1984 (Q) & 51.7 & 52.6 & & $19 . .9 * * *$ & & \\
\hline \multirow{2}{*}{$\begin{array}{l}\text { 2. Scheduled } \\
\text { castes/tribes }\end{array}$} & 2. Cohort 1945-1964 (P) & 51.8 & 49.0 & $22.8 * * *$ & & $9.7 * * *$ & $7.2^{* * *}$ \\
\hline & vs. Cohort 1965-1984 (Q) & 51.0 & 53.7 & & $18.8^{* * *}$ & & \\
\hline \multirow{2}{*}{$\begin{array}{l}\text { 3. Other } \\
\text { Backward Castes }\end{array}$} & 3. Cohort 1945-1964 (P) & 52.5 & 52.0 & $19.8^{* * *}$ & & $6.7 * * *$ & $3.6^{*}$ \\
\hline & vs. Cohort 1965-1984 (Q) & 51.2 & 52.0 & & $19.7^{* * *}$ & & \\
\hline \multirow[t]{2}{*}{ 4. Muslims } & 4. Cohort 1945-1964 (P) & 49.0 & 47.8 & $21.8 * * *$ & & 7.6 & 5.7 \\
\hline & vs. Cohort 1965-1984 (Q) & 47.1 & 48.5 & & $19.8 * * *$ & & \\
\hline
\end{tabular}

Note: $\mathrm{M}$ is total mobility (percent off the main diagonal), $\mathrm{M}^{\prime}$ is total mobility using the marginal frequencies from the $\mathrm{Q}$ matrix. Significance levels for the likelihood ratio $\chi^{2}$ statistic $G^{2}$ (d.f. 9 for $d(P, I), d(Q, I)$, and $d(P, Q)$; 5 for $d^{i}(P, Q)$ ): ***<0.01 **<0.05* $<0.10$. 
Table 6: Components of $d(P, I), d(Q, I)$, and $d(P, Q)$ for sons' birth cohort 1945-64 (P) vs. birth cohort 1965-84 (Q) for different social groups

\begin{tabular}{|c|c|c|c|c|c|c|c|}
\hline Contrast & $d(P, I)$ & $\begin{array}{l}\text { Odds } \\
\text { ratio }\end{array}$ & $d(Q, I)$ & $\begin{array}{l}\text { Odds } \\
\text { ratio }\end{array}$ & $d(P, Q)$ & $\begin{array}{l}\text { Percentage } \\
\text { of total }\end{array}$ & $\begin{array}{l}\text { Cumulative } \\
\text { percentage }\end{array}$ \\
\hline \multicolumn{8}{|l|}{ Social Group: Higher Castes } \\
\hline 1. $[(W F) /(W U)] /[(U F) /(U U)]$ & $1.16^{*}$ & 1.79 & $3.47 * * *$ & 5.66 & $2.30 * * *$ & 13.82 & 13.82 \\
\hline 2. $[(S F) /(S U)] /[(U F) /(U U)]$ & 0.58 & 0.75 & $1.47 * * *$ & 2.09 & $2.05 * * *$ & 10.99 & 24.80 \\
\hline 3. $[(W F) /(W U)] /[(F F) /(F U)]$ & $2.43 * * *$ & 0.30 & 0.62 & 0.73 & $1.81^{* *}$ & 8.53 & 33.33 \\
\hline 4. $[(\mathrm{FF}) /(\mathrm{FS})] /[(\mathrm{SF}) /(\mathrm{SS})]$ & $7.96 * * *$ & 53.42 & $6.17 * * *$ & 21.92 & $1.78 * * *$ & 8.26 & 41.58 \\
\hline 5. $[(\mathrm{FW}) /(\mathrm{FF})] /[(\mathrm{SW}) /(\mathrm{SF})]$ & $7.13 * * *$ & 0.03 & $5.45^{* * *}$ & 0.07 & $1.68 * * *$ & 7.33 & 48.91 \\
\hline 6. $[(\mathrm{SF}) /(\mathrm{SS})] /[(\mathrm{UF}) /(\mathrm{US})]$ & $4.84 * * *$ & 0.09 & $3.26 * * *$ & 0.20 & $1.59 * * *$ & 6.56 & 55.48 \\
\hline 7. $[(\mathrm{FF}) /(\mathrm{FU})] /[(\mathrm{SF}) /(\mathrm{SU})]$ & $4.18^{* * *}$ & 8.07 & $2.61 * * *$ & 3.70 & $1.56^{* *}$ & 6.34 & 61.81 \\
\hline 8. $[(\mathrm{SW}) /(\mathrm{SF})] /[(\mathrm{UW}) /(\mathrm{UF})]$ & $4.42 * * *$ & 9.10 & $2.89 * * *$ & 4.24 & $1.53 * *$ & 6.06 & 67.87 \\
\hline 9. $[(\mathrm{WF}) /(\mathrm{WS})] /[(\mathrm{FF}) /(\mathrm{FS})]$ & $4.97 * * *$ & 0.08 & $3.50 * * *$ & 0.17 & $1.47 * * *$ & 5.65 & 73.51 \\
\hline \multicolumn{8}{|c|}{ Social Group: Scheduled Castes/Tribes } \\
\hline 1. $[(\mathrm{WW}) /(\mathrm{WF})] /[(\mathrm{FW}) /(\mathrm{FF})]$ & $8.30 * * *$ & 63.48 & $5.06 * * *$ & 12.56 & $3.24 * *$ & 11.28 & 11.28 \\
\hline 2. $[(F W) /(F F)] /[(S W) /(S F)]$ & $6.36 * * *$ & 0.04 & $3.14 * * *$ & 0.21 & $3.22 * * *$ & 11.12 & 22.41 \\
\hline 3. $[(W F) /(W U)] /[(F F) /(F U)]$ & $2.50 * *$ & 0.29 & 0.39 & 1.22 & $2.89 * *$ & 8.98 & 31.39 \\
\hline 4. $[(W F) /(W S)] /[(U F) /(U S)]$ & $1.85^{*}$ & 0.40 & $1.01^{*}$ & 1.65 & $2.86^{* *}$ & 8.77 & 40.15 \\
\hline 5. $[(\mathrm{WF}) /(\mathrm{WS})] /[(\mathrm{FF}) /(\mathrm{FS})]$ & $4.96 * * *$ & 0.08 & $2.19 * * *$ & 0.33 & $2.77^{* *}$ & 8.23 & 48.39 \\
\hline 6. $[(W W) /(W F)] /[(U W) /(U F)]$ & $5.37 * * *$ & 14.69 & $2.72 * * *$ & 3.89 & $2.66^{* *}$ & 7.59 & 55.98 \\
\hline 7. $[(S W) /(S F)] /[(U W) /(U F)]$ & $3.43 * * *$ & 5.55 & $0.79 *$ & 1.49 & $2.64 * * *$ & 7.46 & 63.44 \\
\hline 8. $[(W F) /(W U)] /[(U F) /(U U)]$ & 1.92 & 2.62 & $4.54 * * *$ & 9.68 & $2.62 * *$ & 7.36 & 70.81 \\
\hline 9. $[(F F) /(F U)] /[(S F) /(S U)]$ & $3.25 * * *$ & 5.09 & $0.71 * *$ & 1.43 & $2.54 * * *$ & 6.95 & 77.75 \\
\hline 10. $[(\mathrm{SF}) /(\mathrm{SS})] /[(\mathrm{UF}) /(\mathrm{US})]$ & $3.51 * * *$ & 0.17 & $0.99 * * *$ & 0.61 & $2.52 * * *$ & 6.82 & 84.58 \\
\hline 11. $[(\mathrm{FF}) /(\mathrm{FS})] /[(\mathrm{SF}) /(\mathrm{SS})]$ & $6.62 * * *$ & 27.36 & $4.19 * * *$ & 8.11 & $2.43 * * *$ & 6.35 & 90.93 \\
\hline 12. $[(\mathrm{SF}) /(\mathrm{SU})] /[(\mathrm{UF}) /(\mathrm{UU})]$ & $1.17^{*}$ & 1.80 & $3.44^{* * *}$ & 5.58 & $2.27^{* * *}$ & 5.53 & 96.47 \\
\hline \multicolumn{8}{|c|}{ Social Group: Other Backward castes } \\
\hline 1. $[(\mathrm{SF}) /(\mathrm{SU})] /[(\mathrm{UF}) /(\mathrm{UU})]$ & $1.02 * *$ & 1.66 & $3.03 * * *$ & 4.54 & $2.01 * * *$ & 9.09 & 9.09 \\
\hline 2. $[(F W) /(F F)] /[(S W) /(S F)]$ & $6.32 * * *$ & 0.04 & $4.36 * * *$ & 0.11 & $1.96 * * *$ & 8.62 & 17.71 \\
\hline 3. $[(\mathrm{FF}) /(\mathrm{FS})] /[(\mathrm{SF}) /(\mathrm{SS})]$ & $7.08 * * *$ & 34.44 & $5.22 * * *$ & 13.63 & $1.85^{* * *}$ & 7.73 & 25.43 \\
\hline 4. $[(\mathrm{FF}) /(\mathrm{FU})] /[(\mathrm{SF}) /(\mathrm{SU})]$ & $3.28 * * *$ & 5.14 & $1.43^{* * *}$ & 2.04 & $1.85 * * *$ & 7.67 & 33.11 \\
\hline 5. $[(\mathrm{WW}) /(\mathrm{WF})] /[(\mathrm{SW}) /(\mathrm{SF})]$ & 0.04 & 0.98 & $1.66 * * *$ & 2.30 & $1.70^{*}$ & 6.51 & 39.62 \\
\hline 6. $[(\mathrm{WF}) /(\mathrm{WS})] /[(\mathrm{FF}) /(\mathrm{FS})]$ & $4.78^{* * *}$ & 0.09 & $3.10 * * *$ & 0.21 & $1.68^{* *}$ & 6.37 & 45.99 \\
\hline 7. $[(W W) /(W U)] /[(U W) /(U U)]$ & $5.15^{* * *}$ & 13.16 & $6.83^{* * *}$ & 30.48 & $1.68 * *$ & 6.34 & 52.33 \\
\hline 8. $[(W W) /(W S)] /[(S W) /(S S)]$ & $2.26 * * *$ & 3.10 & $3.79 * * *$ & 6.66 & $1.53^{* *}$ & 5.27 & 57.60 \\
\hline 9. $[(S W) /(S F)] /[(U W) /(U F)]$ & $3.05 * * *$ & 4.59 & $1.53 * * *$ & 2.15 & $1.52 * * *$ & 5.18 & 62.78 \\
\hline 10.[(WF)/(WU)]/[(UF)/(UU)] & $2.14 * * *$ & 2.92 & $3.64 * * *$ & 6.18 & $1.50 *$ & 5.03 & 67.81 \\
\hline \multicolumn{8}{|l|}{ Social Group: Muslims } \\
\hline 1. $[(W W) /(W F)] /[(F W) /(F F)]$ & $8.20 * * *$ & 60.23 & $5.42 * * *$ & 14.99 & $2.78^{*}$ & 13.49 & 13.49 \\
\hline 2. $[(W F) /(W U)] /[(U F) /(U U)]$ & 1.97 & 2.68 & $4.41^{* * *}$ & 9.05 & 2.44 & 10.36 & 23.84 \\
\hline 3. $[(\mathrm{WF}) /(\mathrm{WS})] /[(\mathrm{FF}) /(\mathrm{FS})]$ & $5.28 * * *$ & 0.07 & $2.85^{* * *}$ & 0.24 & $2.43^{*}$ & 10.31 & 34.15 \\
\hline
\end{tabular}




\begin{tabular}{llllllll} 
4. $[(\mathrm{WF}) /(\mathrm{WS})] /[(\mathrm{UF}) /(\mathrm{US})]$ & 1.27 & 0.53 & $1.14^{* * *}$ & 1.77 & 2.40 & 10.06 & 44.21 \\
5. $[(\mathrm{WF}) /(\mathrm{WU})] /[(\mathrm{FF}) /(\mathrm{FU})]$ & $2.66^{*}$ & 0.26 & $0.29^{* * *}$ & 0.87 & 2.38 & 9.86 & 54.07 \\
6. $[(\mathrm{FW}) /(\mathrm{FF})] /[(\mathrm{SW}) /(\mathrm{SF})]$ & $6.44^{* * *}$ & 0.04 & $4.34^{* * *}$ & 0.11 & $2.10^{* * *}$ & 7.71 & 61.77 \\
7. $[(\mathrm{WW}) /(\mathrm{WF})] /[(\mathrm{UW}) /(\mathrm{UF})]$ & $3.91^{* * *}$ & 7.07 & $2.08^{* * *}$ & 2.83 & 1.83 & 5.82 & 67.59 \\
\hline
\end{tabular}

Notes: First element of each pair is father's occupation, second is son's. W: White Collar, S: Skilled/Semiskilled, U: Unskilled, F: Farmer. Significance levels for the likelihood ratio $\chi^{2}$ statistic $G^{2}$. ${ }^{* *}<0.01 * *<$ $0.05 *<0.10$. 
Table 7: Comparison of mobility of each social group to total population mobility

\begin{tabular}{|c|c|c|c|c|c|c|}
\hline \multicolumn{7}{|c|}{ Panel 1: Son's Birth Cohort=1945-64 } \\
\hline & $\begin{array}{l}M \\
(1)\end{array}$ & $\begin{array}{l}M^{\prime} \\
(2)\end{array}$ & $\begin{array}{c}d(P, I) \\
(3)\end{array}$ & $\begin{array}{c}d(Q, I) \\
(4)\end{array}$ & $\begin{array}{c}d(P, Q) \\
(5)\end{array}$ & $\begin{array}{c}d^{i}(P, Q) \\
(6)\end{array}$ \\
\hline 1. Higher castes $(P)$ & 52.5 & 53.8 & $21.6 * * *$ & & $3.8^{*}$ & 2.3 \\
\hline vs. All (Q) & 51.9 & 51.2 & & $21.9 * * *$ & & \\
\hline 2. SC/ST (P) & 51.8 & 51.7 & 22.8 & & 3.3 & 1.6 \\
\hline vs. All (Q) & 51.9 & 52.1 & & $21.9 * * *$ & & \\
\hline 3.OBC (P) & 52.5 & 53.4 & $19.8^{* * *}$ & & 3.2 & 1.1 \\
\hline vs. All (Q) & 51.9 & 51.2 & & $21.9 * * *$ & & \\
\hline 4. Muslims (P) & 50.0 & 52.5 & $21.8 * * *$ & & 3.8 & 3.4 \\
\hline vs. All (Q) & 51.9 & 48.4 & & $21.9 * * *$ & & \\
\hline \multicolumn{7}{|c|}{ Panel 2: Son's Birth Cohort=1965-84 } \\
\hline & $\begin{array}{l}M \\
\text { (1) }\end{array}$ & $\begin{array}{l}M^{\prime} \\
(2)\end{array}$ & $\begin{array}{c}d(P, J) \\
(3)\end{array}$ & $\begin{array}{c}d(Q, J) \\
(4)\end{array}$ & $\begin{array}{c}d(P, Q) \\
(5)\end{array}$ & $\begin{array}{c}\operatorname{di}(P, Q) \\
(6)\end{array}$ \\
\hline 1. Higher castes $(P)$ & 51.7 & 51.8 & $19.9 * * *$ & & $3.7^{* * *}$ & $3.0 * *$ \\
\hline vs. All (Q) & 50.8 & 50.8 & & $20.3 * * *$ & & \\
\hline 2. SC/ST (P) & 51.0 & 53.4 & $18.8^{* * *}$ & & $3.4^{* * *}$ & 2.2 \\
\hline vs. All (Q) & 50.8 & 48.8 & & $20.3 * * *$ & & \\
\hline 3.OBC (P) & 51.2 & 51.2 & $19.7^{* * *}$ & & 1.9 & 1.8 \\
\hline vs. All (Q) & 50.8 & 50.8 & & $20.3^{* * *}$ & & \\
\hline 4. Muslims (P) & 47.1 & 50.1 & $19.8 * * *$ & & 2.9 & 2.0 \\
\hline vs. All (Q) & 50.8 & 47.5 & & $20.3 * * *$ & & \\
\hline
\end{tabular}

Note: $\mathrm{M}$ is total mobility (percent off the main diagonal), $\mathrm{M}^{\prime}$ is total mobility using the marginal frequencies from the $Q$ matrix. Significance levels for the likelihood ratio $\chi^{\wedge} 2$ statistic $G^{\wedge} 2$ (d.f. 9 for $d(P, I), d(Q, I)$, and $d(P, Q) ; 5$ for di $(P, Q)$ ): $* * *<0.01 * *<0.05 *<0.10$. 
Table 8: Comparison of mobility of disadvantage groups to higher castes mobility

\begin{tabular}{|c|c|c|c|c|c|c|}
\hline \multicolumn{7}{|c|}{ Panel I: Son's Birth Cohort=1945-64 } \\
\hline & $\begin{array}{l}M \\
\text { (1) }\end{array}$ & $\begin{array}{l}M^{\prime} \\
(2)\end{array}$ & $\begin{array}{c}d(\mathbf{P}, \mathbf{I}) \\
(3)\end{array}$ & $\begin{array}{c}d(Q, I) \\
(4)\end{array}$ & $\begin{array}{c}d(P, Q) \\
(5)\end{array}$ & $\begin{array}{c}d^{i}(P, Q) \\
(6)\end{array}$ \\
\hline 1. SC/ST (P) & 51.8 & $\begin{array}{c}50.7 \\
(54.2)\end{array}$ & $22.8^{* * *}$ & & $5.7 * *$ & 2.5 \\
\hline 2.OBC (P) & 52.5 & $\begin{array}{c}53.0 \\
(52.9)\end{array}$ & $19.8 * * *$ & & 4.1 & 2.5 \\
\hline 3. Muslims (P) & 49.0 & $\begin{array}{c}51.4 \\
(50.0)\end{array}$ & $21.8 * * *$ & & 6.2 & 5.4 \\
\hline vs. Higher castes (Q) & 52.5 & & & $21.6 * * *$ & & \\
\hline \multicolumn{7}{|c|}{ Panel 2: Son's Birth Cohort=1965-84 } \\
\hline & $\begin{array}{l}M \\
(1)\end{array}$ & $\begin{array}{l}M^{\prime} \\
(2)\end{array}$ & $\begin{array}{c}d(P, I) \\
(3)\end{array}$ & $\begin{array}{c}d(Q, I) \\
(4)\end{array}$ & $\begin{array}{c}d(P, Q) \\
(5)\end{array}$ & $\begin{array}{c}d^{i}(P, Q) \\
(6)\end{array}$ \\
\hline 1. SC/ST (P) & 51.0 & $\begin{array}{c}53.4 \\
(49.8)\end{array}$ & $18.8^{* * *}$ & & $6.5^{* * *}$ & $5.1 * * *$ \\
\hline 2.OBC (P) & 51.2 & $\begin{array}{c}51.1 \\
(51.6)\end{array}$ & $19.7 * * *$ & & $4.2^{* *}$ & $3.8^{* *}$ \\
\hline 3. Muslims (P) & 47.1 & $\begin{array}{c}50.4 \\
(48.3)\end{array}$ & $19.8 * * *$ & & $4.8^{*}$ & $4.7^{*}$ \\
\hline vs. Higher castes (Q) & 51.7 & & & $19.9 * * *$ & & \\
\hline
\end{tabular}

Note: $\mathrm{M}$ is total mobility (percent off the main diagonal), $\mathrm{M}^{\prime}$ is total mobility using the marginal frequencies from the $Q$ matrix. The numbers in parenthesis are mobility in $Q$ using marginal frequencies from $P$. Significance levels for the likelihood ratio $\chi^{2}$ statistic $G^{2}$ (d.f. 9 for $d(P, I)$, $d(Q, I)$, and d(P,Q); 5 for $\operatorname{di}(P, Q)$ ): *** $<0.01 * *<0.05 *<0.10$. 
Table 9: Components of $d(P, I), d(Q, I)$, and $d(P, Q)$ for SC/ST (P) vs. higher castes (Q)

\begin{tabular}{|c|c|c|c|c|c|c|c|}
\hline \multicolumn{8}{|l|}{ Panel 1: Birth Cohort 1945-1964 } \\
\hline Contrast & $d(P, I)$ & $\begin{array}{l}\text { Odds } \\
\text { ratio }\end{array}$ & $d(Q, I)$ & $\begin{array}{l}\text { Odds } \\
\text { ratio }\end{array}$ & $d(P, Q)$ & $\begin{array}{l}\text { Percentage } \\
\text { of total }\end{array}$ & $\begin{array}{l}\text { Cumulative } \\
\text { percentage }\end{array}$ \\
\hline 1. $[(W W) /(W F)] /[(S W) /(S F)]$ & 1.9 & 2.6 & 0.1 & 0.9 & 2.1 & 12.9 & 12.9 \\
\hline 2. $[(W W) /(W U)] /[(U W) /(U U)]$ & $7.3^{* * *}$ & 38.4 & $5.5 * * *$ & 15.4 & $1.8^{* *}$ & 10.2 & 23.2 \\
\hline 3. $[(S F) /(S U)] /[(U F) /(U U)]$ & $1.2^{*}$ & 1.8 & 0.6 & 0.7 & $1.8^{* *}$ & 9.4 & 32.6 \\
\hline 4. $[(\mathrm{FF}) /(\mathrm{FS})] /[(\mathrm{SF}) /(\mathrm{SS})]$ & $6.6 * * *$ & 27.4 & $8.0 * * *$ & 53.4 & $1.3^{*}$ & 5.5 & 38.1 \\
\hline 5. $[(\mathrm{SF}) /(\mathrm{SS})] /[(\mathrm{UF}) /(\mathrm{US})]$ & $3.5^{* * *}$ & 0.2 & $4.8^{* * *}$ & 0.1 & 1.3 & 5.5 & 43.6 \\
\hline 6. $[(W F) /(W S)] /[(S F) /(S S)]$ & 1.7 & 2.3 & $3.0 * * *$ & 4.5 & 1.3 & 5.4 & 49.0 \\
\hline 7. $[(\mathrm{WW}) /(\mathrm{WS})] /[(\mathrm{FW}) /(\mathrm{FS})]$ & $3.3 * * *$ & 5.3 & $2.1 * * *$ & 2.8 & $1.3^{* *}$ & 5.1 & 54.1 \\
\hline 8. $[(W W) /(W F)] /[(F W) /(F F)]$ & $8.3 * * *$ & 63.5 & $7.0 * * *$ & 33.6 & 1.3 & 5.0 & 59.1 \\
\hline 9. $[(\mathrm{WW}) /(\mathrm{WU})] /[(\mathrm{FW}) /(\mathrm{FU})]$ & $5.8 * * *$ & 18.2 & $4.6 * * *$ & 10.0 & 1.2 & 4.5 & 63.5 \\
\hline 10.[(WW)/(WS)]/[(UW)/(US)] & $3.5 * * *$ & 5.8 & $2.5 * * *$ & 3.4 & $1.1^{*}$ & 3.5 & 67.1 \\
\hline 11.[(WW)/(WF)]/[(UW)/(UF)] & $5.4 * * *$ & 14.7 & $4.3^{* * *}$ & 8.6 & 1.1 & 3.5 & 70.5 \\
\hline 12. $[(\mathrm{WW}) /(\mathrm{WU})] /[(\mathrm{SW}) /(\mathrm{SU})]$ & $2.7 * * *$ & 3.9 & $1.6 * * *$ & 2.3 & 1.1 & 3.5 & 74.0 \\
\hline 13. $[(W F) /(W U)] /[(S F) /(S U)]$ & 0.8 & 1.5 & $1.7^{* *}$ & 2.4 & 1.0 & 3.0 & 77.0 \\
\hline \multicolumn{8}{|l|}{ Panel 2: Birth Cohort 1965-84 } \\
\hline 1. $[(F W) /(F F)] /[(S W) /(S F)]$ & $3.1 * * *$ & 0.2 & $5.5^{* * *}$ & 0.1 & $2.3^{* * *}$ & 12.7 & 12.7 \\
\hline 2. $[(\mathrm{SF}) /(\mathrm{SS})] /[(\mathrm{UF}) /(\mathrm{US})]$ & $1.0 * * *$ & 0.6 & $3.3 * * *$ & 0.2 & $2.3 * * *$ & 12.1 & 24.8 \\
\hline 3. $[(S W) /(S F)] /[(U W) /(U F)]$ & $0.8^{*}$ & 1.5 & $2.9 * * *$ & 4.2 & $2.1 * * *$ & 10.4 & 35.2 \\
\hline 4. $[(F F) /(F S)] /[(S F) /(S S)]$ & $4.2 * * *$ & 8.1 & $6.2 * * *$ & 21.9 & $2.0 * * *$ & 9.4 & 44.6 \\
\hline 5. $[(\mathrm{SF}) /(\mathrm{SU})] /[(\mathrm{UF}) /(\mathrm{UU})]$ & $3.4 * * *$ & 5.6 & $1.5^{* * *}$ & 2.1 & $2.0 * * *$ & 9.1 & 53.7 \\
\hline 6. $[(F F) /(F U)] /[(S F) /(S U)]$ & $0.7^{* *}$ & 1.4 & $2.6 * * *$ & 3.7 & $1.9 * * *$ & 8.6 & 62.3 \\
\hline 7. $[(W W) /(W F)] /[(S W) /(S F)]$ & $1.9 * * *$ & 2.6 & $0.3^{* * *}$ & 1.2 & $1.6 * * *$ & 6.1 & 68.4 \\
\hline 8. $[(W F) /(W S)] /[(U F) /(U S)]$ & $1.0^{*}$ & 1.7 & $0.6 * * *$ & 0.7 & $1.6^{* *}$ & 5.9 & 74.3 \\
\hline 9. $[(\mathrm{WF}) /(\mathrm{WS})] /[(\mathrm{FF}) /(\mathrm{FS})]$ & $2.2^{* * *}$ & 0.3 & $3.5^{* * *}$ & 0.2 & $1.3^{* *}$ & 4.0 & 78.3 \\
\hline
\end{tabular}

Notes: First element of each pair is father's occupation, second is son's. W: White Collar, S: Skilled/Semiskilled, U: Unskilled, F: Farmer. Significance levels for the likelihood ratio $\chi^{2}$ statistic $G^{2}{ }^{* * *}<0.01 * *<$ $0.05 *<0.10$. 


\section{Data Appendix}

The India Human Development Survey (IHDS) survey first asks questions about different sources of household income. It then immediately asks which household members participated in each of those work activities and the level of their participation. For example, whether the household engaged in farming or gardening in the past year and, if so, who worked on these farms, and how many days and hours they worked; whether any members of the household worked for payment, in cash or kind, and details about the work. The IHDS line of questioning provides results that are broadly similar, although not identical, to the work participation rates given by the 'usual status' employment questions used by the NSS or Census. (Desai et al., 2010). IHDS data also contain created indicators for occupations such as wage/salary workers (wkagwage: agriculture wage labor; wknonag: nonagricultural wage labor; wksalary: salaried position), self-employed persons (wkbusiness: work in household business), farmers (wkfarm: family farm work), or animal care workers (wkanimal: animal care). These indicators are based on if an individual had spent more than 240 hours in the particular work (for further details, see Chapter 4 of Desai et al., 2010). ${ }^{19}$ These are not mutually exclusive groups, and there exists some overlap between different work categories.

The 2-digit occupation codes are also provided in data in case if workers are wage/salaried workers (ws3a variable) or are self-employed in own business (nflb variable). We classified workers as wage/salary workers if worker had spent more than or equal to 240 hours in wage/salary (salary works, wage works in agriculture or non-agriculture sectors) works in the past year. A worker is self-employed worker if he has not been classified as wage/salary worker but has been classified as self-employed workers. A worker is classified as farmers if he is not classified as wage/salaried or self-employed, and works on his own farm. ${ }^{20} \mathrm{~A}$ worker occupation will be classified as animal workers if workers are not

\footnotetext{
${ }^{19}$ The time spent was not collected for animal workers, but the options were never, sometimes, and usually. Animal workers (wkanimal is defined in data as one if individual spent sometimes or usually for animal care).

${ }^{20}$ The distribution of occupation remains similar if we use the majority time spent criterion. For example, in our final sample, if we use majority time criterion 322 out of 25610 wage salaried workers may be classifies as self-
} 
classified in the first three categories, and reported to have taken care of animals usually. ${ }^{21}$ In case of wage salaried workers and self-employed workers, we used the 2-digit occupation codes given in data (ws3a and nflb) to disaggregate workers, while for farmers and animal care workers; we imputed the two digits codes (62: who work on own farm, and 65: animal care workers). Once we have two digit occupation codes for all workers, we use those to reclassify in four groups of workers (white collar, skilled/semi-skilled, unskilled, and farmers). ${ }^{22}$

To get the occupation of fathers, we use following information (see appendix1, Table 1). First, majority of adult male members are heads of the household and their fathers are not living in the same household (except for few cases). The IHDS data collected information about occupation and education of father/husband of household head---Question 1.19 and 1.20 on page 3 of household questionnaire (id19 and id20 variable in data). As our sample is restricted to men, the id19 variable provides information about occupation of fathers of the heads. ${ }^{23}$ Second, the fathers of few individuals, especially for the younger men, live in the same household (parent id reported in data), and hence we know their occupation if they have reported working. Third, we exploit relation to head variable to get fathers occupation for some individuals. For example,

employed workers. The overlap with farmers is somewhat higher. However, on closer look, majority of these overlap is because of agriculture labor/daily workers who work for wages (hence classified as wage/salary workers) working on their own farm also. These individuals are more likely marginal farmers and closer to agricultural laborers than farmers. Hence we preferred to categorize them as reported through wage earning status rather than farmers.

${ }^{21}$ For animal care work, there is no number of days or hours reported. However, question 5.5 (variable an6 in data) on page 10 of household questionnaire asks how often the person take care of the animals with possible answer of never, sometimes, or usually. The IHDS data provide a category wkanimal: animal care worker if the worker take care of animals sometimes or usually. IHDS data define people as working (wkany variable in data) if they were engaged for at least 240 hours during the preceding year in one or more gainful activities, such as working in household farms or businesses, or for a wage or salary, or persons who sometimes or usually take care of animals. However, we only classified those workers as animal care workers who were not classified as wage/salary, selfemployed business, or farmers based on 240 hours work criterion and reported that they usually take care of animals. As a result the number of workers based on our categories is lower than number of workers based on IHDS data wkany indicator.

${ }^{22}$ See appendix 2 for exact reclassification.

${ }^{23}$ Id19b variable in data provide text description of the occupation. The author found few discrepancies in id19 variable based on id 19b description, and corrected accordingly few cases where the discrepancy seems obvious, e.g., in few cases text description says agriculture labor, while the id19 is coded as 3 (3: Engineering Technicians) whereas the actual code for agricultural laborers is 63 . 
if an individuals has reported as brother of head (male headed households) of the household, for that individual, the father is same person as household head's father (for who, we have information from id19 variable). 


\section{Appendix-I}

Table A1: Construction of son-father sample

Total Number of individuals surveyed in 2005

IHDS

215,784

Male in age group 21-60

52,816

\begin{tabular}{rrrrr}
\hline \multicolumn{6}{c}{ Birth Cohorts } \\
\hline $1945-54$ & $1955-64$ & $1965-74$ & $1975-84$ & All \\
7,823 & 11,202 & 14,918 & 18,873 & $\mathbf{5 2 , 8 1 6}$ \\
1,320 & 815 & 1,154 & 4,099 & 7,388 \\
16.9 & 7.3 & 7.7 & 21.7 & 14.0 \\
\hline 6,503 & 10,387 & 13,764 & 14,774 & 45,428 \\
\hline
\end{tabular}

A)Total number of men in 21-60 age group

B) Occupation information missing (dropped) ${ }^{1}$

(B) as percentage of (A)

Panel I: Total number of men (21-60 age group)

with occupation information

Identification of father

a) Individual is head of the household ${ }^{2}$

6,143

9,384

9,725

4,189

29,441

Individual is household head and father of head is

living in household

(84)

(381)

(634)

(308)

(1407)

b) Individuals who are not household heads, however whose father is living in the household ${ }^{3}$

$\begin{array}{lllll}66 & 601 & 2,981 & 8,542 & 12,190\end{array}$

c) Individual is neither head of the household nor his father is living in household (no father id is provided $)^{4}$

Total number of men (21-60 age group) whose

father is identified

$\begin{array}{lllll}6,289 & 10,271 & 13,600 & 14,455 & 44,615\end{array}$

Percentage of working men (21-60 age group, panel I) whose fathers are not identified

Although father identified, but occupation information of father is missing (dropped)

Panel II: Number of son-father pair with occupation information (Final Sample)

\begin{tabular}{llllll}
\hline Panel II as \% of Panel I & 89.2 & 87.6 & 82.5 & 81.5 & 84.3 \\
\hline \hline $\begin{array}{l}\text { Final sample size (son-father pair) as \% of sons } \\
\text { cohort size }\end{array}$ & 74.1 & 81.3 & 76.1 & 63.8 & 72.5 \\
\hline
\end{tabular}

Notes: 1) We do not know occupation of individuals who have not worked in the past year. Based on IHDS definition of working, about 1282, 746, 1050, and 3912 individuals in cohort 1945-54, 1955-64, 1975-84 reported not working. As discussed in Data Appendix, our measure of workers marginally underestimates the number of workers. 825 individuals in cohort 1975-84 (age 21-30) reported as students and just counted as not working.

2) IHDS collected information about occupation and education of father/husband of household head, Question 1.19 and 1.20 on page 3 of household questionnaire (id19 and id20 variable in data).

3) If father of an individual is living in household, Question 2.8 on page 4 of household questionnaire provide father id in household roster (ro8 variable in data).

4) For these individuals, identification of father is achieved through use of relation to head variable. For example, individuals who reported as brothers of head (male headed households), that individual father is same person as household head father (for who, we have information as reported in note 1). 
Table A2: Summary Measures of Mobility using nine occupation groups

\begin{tabular}{|c|c|c|c|c|c|c|}
\hline & $\begin{array}{l}M \\
(1)\end{array}$ & $\begin{array}{l}M^{\prime} \\
(2)\end{array}$ & $\begin{array}{c}d(P, I) \\
(3)\end{array}$ & $\begin{array}{c}d(Q, I) \\
(4)\end{array}$ & $\begin{array}{c}d(P, Q) \\
(5)\end{array}$ & $\begin{array}{c}\mathrm{d}^{\mathrm{i}}(\mathrm{P}, \mathrm{Q}) \\
(6)\end{array}$ \\
\hline 1. Cohort 1945-1954 (P) & 44.7 & 50.3 & $110.2 * * *$ & & 57.6 & 55.8 \\
\hline vs. Cohort 1955-1964 (Q) & 50.7 & 45.1 & & $104.3^{* * *}$ & & \\
\hline 2. Cohort 1955-1964 (P) & 50.7 & 52.4 & $104.2 * * *$ & & 41.1 & 40.4 \\
\hline vs. Cohort 1965-1974 (Q) & 52.7 & 50.8 & & $98.8^{* * *}$ & & \\
\hline 3. Cohort 1965-1974 (P) & 52.7 & 48.6 & $98.8 * * *$ & & $40.1 * * *$ & 35.6 \\
\hline vs. Cohort 1975-1984 (Q) & 48.2 & 52.6 & & $98.8^{* * *}$ & & \\
\hline 4. Cohort 1945-1954 (P) & 44.7 & 47.2 & $110.2 * * *$ & & $58.2 * * *$ & $54.0 * * *$ \\
\hline vs. Cohort 1975-1984 (Q) & 48.2 & 45.6 & & $98.8 * * *$ & & \\
\hline
\end{tabular}

Note: $\mathrm{M}$ is total mobility (percent off the main diagonal), $\mathrm{M}^{\prime}$ is total mobility using the marginal frequencies from the $\mathrm{Q}$ matrix. Significance levels for the likelihood ratio $\chi^{2}$ statistic $G^{2}$ (d.f. 64 for $d(P, J), d(Q, J)$, and $d(P, Q)$; and 56 for di(P,Q). $* * *<0.01 * *<0.05 *<0.10$. 


\section{Appendix 2: Classification of occupation}

\begin{tabular}{|c|c|}
\hline \multicolumn{2}{|r|}{ White Collar } \\
\hline $\begin{array}{l}\text { NCAER } \\
\text { Occupation } \\
\text { Code }\end{array}$ & Description \\
\hline \multicolumn{2}{|c|}{ Division 0-1: PROFESSIONAL and TECHNICAL } \\
\hline 0 & Physical Scientists \\
\hline 1 & Physical Science Technicians \\
\hline 2 & Architects, Engineers, Technologists and Surveyors \\
\hline 3 & Engineering Technicians \\
\hline 4 & Aircraft and Ships Officers \\
\hline 5 & Life Scientists \\
\hline 6 & Life Science Technicians \\
\hline 7 & Physicians and Surgeons \\
\hline 8 & Nursing and other Health Technicians \\
\hline 9 & Scientific, Medical and Technical Persons, Other \\
\hline 10 & Mathematicians, Statisticians and Related Workers \\
\hline 11 & Economists and Related Workers \\
\hline 12 & Accountants, Auditors and Related Workers \\
\hline 13 & Social Scientists and Related Workers \\
\hline 14 & Jurists \\
\hline 15 & Teachers \\
\hline 16 & Poets, Authors, Journalists and Related Workers \\
\hline 17 & Sculptors, Photographers and Creative Artists \\
\hline 18 & Composers and Performing Artists \\
\hline 19 & Professional Workers, n.e.c. \\
\hline
\end{tabular}

Division 2: MANAGERS

20 Elected and Legislative Officials

21 Administrative Officials Government and Local Bodies

22 Managers and Working Proprietors, Wholesale and Retail Trade

23 Managers and Directors, Financial Institutions

\section{Skilled/Semi-Skilled}

\section{NCAER}

Occupation

Code

Description

Division 3: CLERICAL

30 Clerical, Transport, and Communication Supervisors

31 Village Officials

32 Stenographers and Typists

33 Book-keepers, Cashiers and Related Workers

34 Computing Machine Operators

35 Clerical and Related Workers, n.e.c.

36 Transport and Communication Supervisors

37 Transport Conductors and Guards

38 Mail Distributors and Related Workers

39 Telephone and Telegraph Operators

Division 4: SALES

40 Merchants and Shopkeepers, Wholesale and Retail Trade

41 Manufacturers, Agents

42 Technical Sales and Commercial Travellers

43 Sales, Shop Assistants and Related Workers

44 Insurance, Real Estate, Securities and Business Service Sales

45 Money Lenders and Pawn Brokers

49 Sales Workers, n.e.c.

Division 7-8-9: PRODUCTION, TRANSPORT EQUIPMENT, and LABOURERS (Labourers-99, are classified in unskilled group)

71 Miners, Quarrymen, Well Drillers and Related Workers

72 Metal Processors

73 Wood Preparation Workers and Paper Makers

74 Chemical and Related Workers

75 Spinners, Weavers, Knitters, Dyers and Related Workers

76 Tanners, Fellmongers and Pelt Dressers 
24 Managers and Working Proprietors, Construction and Manufacturing Managers and Working Proprietors, Transport, Storage and

25 Communication

26 Managers and Working Proprietors, Other Service

29 Administrative, Executive and Managerial Workers, n.e.c.

\section{Unskilled}

Division 5: SERVICE

50 Hotel and Restaurant Keepers

51 House Keepers, Matron and Stewards (Domestic and Institutional) Cooks, Waiters, Bartenders and Related Worker (Domestic and

52 Institutional)

53 Maids and Other House Keeping Service Workers n.e.c.

54 Building Caretakers, Sweepers, Cleaners and Related Workers

55 Launderers, Dry-cleaners and Pressers

56 Hair Dressers, Barbers, Beauticians and Related Workers

57 Protective Service Workers

59 Service Workers, n.e.c.

63 Agricultural Labourers

64 Plantation Labourers and Related Workers

65 Other Farm Workers

66 Forestry Workers

67 Hunters and Related Workers

68 Fishermen and Related Workers

99 Labourers, n.e.c.
77 Food and Beverage Processors

78 Tobacco Preparers and Tobacco Product Makers

79 Tailors, Dress Makers, Sewers, Upholsterers and Related Worker

80 Shoemakers and Leather Goods Makers

81 Carpenters, Cabinet and Related Wood Workers

82 Stone Cutters and Carvers

83 Blacksmiths, Tool Makers and Machine Tool Operators Machinery Fitters, Assemblers and Precision Instrument Makers (exc.

84 Electrical)

85 Electrical Fitters and Related Electrical Workers

86 Broadcasting, Sound Equipment, and Cinema Operators

87 Plumbers, Welders, Sheet Metal and Structural Metal Workers

88 Jewellery and Precious Metal Workers and Metal Engravers

89 Potters, Glass Formers, and Related Workers

90 Rubber and Plastic Product Makers

91 Paper and Paper Board Products Makers

92 Printing and Related Workers

93 Painters

94 Production and Related Workers, n.e.c.

95 Bricklayers and Other Construction Workers

96 Stationery Engines Operators, Oilers and Greasers

97 Material Handling, Loaders and Unloaders

98 Transport Equipment Operators

\section{Farmers}

60 Farm Managers and Supervisors

61 Cultivators

62 Farmers other than Cultivators 